\title{
Stem Cell Therapy Potency in Personalizing Severe COVID-19 Treatment
}

\author{
Arefeh Basiri $^{1,2} \cdot$ Fatemeh Mansouri $^{3,4,2} \cdot$ Arezo Azari $^{5,2} \cdot$ Parviz Ranjbarvan $^{6,2} \cdot$ Fateme Zarein $^{7,2} \cdot$ Arash Heidari $^{8,2}$. \\ Ali Golchin ${ }^{6,2}$ (1)
}

Accepted: 16 December 2020 / Published online: 28 January 2021

(C) The Author(s), under exclusive licence to Springer Science+Business Media, LLC part of Springer Nature 2021

\begin{abstract}
Currently, there are no specific and efficient vaccines or drugs for COVID-19, particularly in severe cases. A wide range of variations in the clinical symptoms of different patients attributed to genomic differences. Therefore, personalized treatments seem to play a critical role in improving these symptoms and even similar conditions. Prompted by the uncertainties in the area of COVID-19 therapies, we reviewed the published papers and concepts to gather and provide useful information to clinicians and researchers interested in personalized medicine and cell-based therapy. One novel aspect of this study focuses on the potential application of personalized medicine in treating severe cases of COVID-19. However, it is theoretical, as any real-world examples of the use of genuinely personalized medicine have not existed yet. Nevertheless, we know that stem cells, especially MSCs, have immune-modulatory effects and can be stored for future personalized medicine applications. This theory has been conjugated with some evidence that we review in the present study. Besides, we discuss the importance of personalized medicine and its possible aspects in COVID-19 treatment, then review the cell-based therapy studies for COVID-19 with a particular focus on stem cell-based therapies as a primary personalized tool medicine. However, the idea of cell-based therapy has not been accepted by several scientific communities due to some concerns of lack of satisfactory clinical studies; still, the MSCs and their clinical outcomes have been revealed the safety and potency of this therapeutic approach in several diseases, especially in the immune-mediated inflammatory diseases and some incurable diseases. Promising outcomes have resulted in that clinical studies are going to continue.
\end{abstract}

Keywords COVID-19 $\cdot$ Personalized medicine $\cdot$ Cell-based therapy $\cdot$ Stem cell

This article belongs to the Topical Collection: Special Issue on COVID-

19 Pandemic and Stem Cells

Guest Editor: Mariusz Z. Ratajczak

Ali Golchin

agolchin.vet10@yahoo.com; golchin.a@umsu.ac.ir

1 Department of Biomaterials and Tissue Engineering, School of Advanced Technologies in Medicine, Isfahan University of Medical Sciences, Isfahan, Iran

2 Regenerative Medicine Group (REMED), Universal Scientific Education and Research Network (USERN), Tehran, Iran

3 Department of Genetics and Immunology, Faculty of Medicine, Urmia University of Medical Sciences, Urmia, Iran

4 Cellular and Molecular Research Center, Urmia University of Medical Sciences, Urmia, Iran
5 Department of Tissue engineering and Applied Cell Sciences, School of Advanced Technologies in Medicine, Shahid Beheshti University of Medical Sciences, Tehran, Iran

6

Department of Clinical Biochemistry and Applied Cell Sciences, Faculty of Medicine, Urmia University of Medical Sciences, Urmia, Iran

7 Department of Nanobiotechnology, faculty of biological sciences, Tarbiat Modares University, Tehran, Iran

8 School of Medicine, Tehran University of Medical Sciences, Tehran, Iran 


\section{Introduction}

Coronavirus disease (COVID-19) is a newly appeared disease with severe respiratory morbidity and mortality found in Wuhan, China, for the first time and then rapidly spread throughout the world [1]. The illness was caused by an enveloped RNA virus named severe acute respiratory syndrome coronavirus 2 (SARS-CoV-2) [2, 3]. Contaminated surfaces, as well as respiratory droplets, can result in transmission among humans [4]. Despite preventive efforts, the number of new cases and mortality are continuously increasing worldwide [2]. COVID-19 is still known as a communicable disease with high complexity [5].

Novel coronavirus infection is a severe pulmonary disease with some symptoms overlapping with SARS-Cov-1, H1N1, and influenza (Table 1). Individuals with age over 60 years, underlying health conditions such as cancer, lung and heart disease, immunocompromised and blood disorders, and impaired glucose tolerance or diabetes mellitus have been identified so far as being more susceptible to severe COVID-19 $[14,15]$. Besides, recently have identified the $3 \mathrm{p} 21.31$ gene cluster as a genetic susceptibility locus for severe COVID19 patients' respiratory failure [16]. The symptoms of COVID-19 could be mild, including fever (82\%) and cough (81\%) and severe, which are characterized by acute respiratory distress syndrome (ARDS) and cytokine storm (14\%). Finally, some severe cases suffer from multiple organ failure involving heart, kidney, liver, gastrointestinal system, and sometimes mortality $[17,18]$. The pathogenesis of SARS-CoV-2 is caused by its spike protein, which recognizes the angiotensin I converting enzyme-2 receptor (ACE2), Then, prim by the cellular transmembrane protease, serine 2 (TMPRSS2) to enter host cells and spread [5, 19-21]. The "Cytokine storm" is a hyper-inflammatory response in ARDS. Besides, ACE2 expression in other tissues, including the heart, liver, kidney, and gastrointestinal organs, may cause multiple organ failures (i.e., myocardial injury, arrhythmia, acute kidney injury) lead to shock and death of affected patients [5, 22]. Moreover, the elevation of cardiac troponin I (CTnI)/ creatine kinasemyocardial band (CK-MB) in cardiac damage, aspartate transaminase (AST)/alanine transaminase (ALT) in liver damage, C-reactive protein and cytokines during inflammation, stress, or pathogen attack play vital role to predict the risk of severe pneumonia and follow up patients in batting COVID-19 disease [23-25].

There are no specific and efficient vaccines or drugs for COVID19, especially in severe cases [26]. However, so many efforts in this field have been continuing. A range of antiviral drugs for treating other diseases is utilized for COVID-19, such as Remdesivir and Favipiravir. On October 22, 2020, U.S. Food and Drug Administration (FDA) approved Remdesivir as the first antiviral drug for application in adults and pediatric patients (include in $\leq 12$ years and weighing at $\leq 40 \mathrm{~kg}$ ) for the treatment of COVID-19 patients needing hospitalization [27]. Given that very few existing antiviral drugs have shown therapeutic effects for COVID-19, finding a suitable antiviral drug is uncertain.

On the other hand, criteria such as safety, efficacy, producibility, and even cost are the main considerable points in drug discovery. However, the main side effects of Remdesivir in the FDA documents have been mentioned hypersensitivity reactions and increasing in levels of liver enzymes [27], but in a randomized, open-label, phase III clinical trial including confirmed hospitalized COVID-19 patients, the most common adverse events were reported as elevating alanine aminotransferase level (7\%), worsening respiratory
Table $1 *$ an overview of different epidemiological information compared with the H1N1, SARS-CoV, MERS-CoV, and SARS-CoV-2 outbreaks

\begin{tabular}{|c|c|c|c|c|c|}
\hline Virus & $\begin{array}{l}\text { SARS- } \\
\text { CoV-2 }\end{array}$ & $\begin{array}{l}\text { SARS- } \\
\text { CoV }\end{array}$ & $\begin{array}{l}\text { MERS- } \\
\text { CoV }\end{array}$ & $\begin{array}{l}\text { H1N1(Pandemic } \\
\text { influenza 1918) }\end{array}$ & $\begin{array}{l}\text { New H1N1 (Pandemic } \\
\text { influenza 2009) }\end{array}$ \\
\hline R0 & $1 \cdot 8-3 \cdot 6$ & $2 \cdot 0-3 \cdot 0$ & $0 \cdot 9$ & $\leq 2$ & 1.2 to 1.6 \\
\hline CFR & Unknown & 9.5 & 34.4 & $1-2 \%$ & $0.04 \%$ \\
\hline Incubation time & $4-12$ & $2-7$ & 6 & Unknown & 2 \\
\hline $\begin{array}{l}\text { Hospitalization } \\
\text { Rate }(\%)\end{array}$ & $\sim 19$ & $\begin{array}{c}\text { most } \\
\quad \text { cas- } \\
\text { es }\end{array}$ & $\begin{array}{l}\text { most } \\
\text { cases }\end{array}$ & 2 & $1-2 \%$ \\
\hline $\begin{array}{l}\text { Antiviral } \\
\text { Therapy }\end{array}$ & Remdesivir & None & None & - & $\begin{array}{l}\text { Peramivir, Zanamivir, } \\
\text { Oseltamivir, Baloxavir }\end{array}$ \\
\hline Vaccine & Ongoing** & None & None & - & $\begin{array}{l}4 \text { Injectable Vaccines, } 1 \\
\text { Intranasal Vaccine }\end{array}$ \\
\hline
\end{tabular}

R0: Basic Reproduction Number; CFR: Case Fatality Rate; Incubation time: The time elapsed between exposure to a pathogenic virus and when symptoms and signs are first obvious

*The data obtained from [6-13]

**Since November 2020, according to the World Health Organization protocol, there are 47 and 155 candidate vaccines in clinical and preclinical evaluation, respectively 
failure (8\%), nausea (9\% of patients), and constipation (7\%) [28]. The FDA recently approved chloroquine phosphate and hydroxychloroquine sulfate for emergency use of COVID-19 treatment; however, its efficacy was unavailable, so the FDA revoked the emergency use authorization for these drugs which are unseemly effective in treating COVID-19 [29]. Further, it is known that a combination of several drugs can better improve the efficiency of therapies, although they are associated with some side effects. Other treatment options are plasma therapies, immunotherapies, monoclonal antibodies, and small molecule-based therapies [30]. Furthermore, in the case of cell therapies, Natural killer (N.K.) cells [30] and MSCs [1], as well as MSC-derived-conditioned media (CM) or extracellular vesicles (E.V.s), are considered [17]. Immunomodulation and immunosuppressive treatments are suggested to be appropriate to decrease cytokine storm symptoms [30].

The rate of susceptibility and progression of the coronavirus is different among the population [31]. The virus's pathogenesis depends on the interaction between host immune genetic factors, environmental and virus agents. It is urgent; we need to anticipate who is at high risk, who has underlying clinical treatment or who develops pneumonia complications, and finally, what is the outcome or response to medical treatments in every person. Genomic variation in angiotensinconverting enzyme2 (ACE2) receptors in target organs between individuals in a family, region, and different populations of countries contribute to the susceptibility to COVID-19 and responsible for all medical treatments. Coronavirus has a heterogeneous behavior, and many genes and receptors are involved in the development of infectious in the host cell $[16,32,33]$. Transmission of the virus from one person to another can increase point mutations in the virus genome and cause different symptoms and severe disease risks in affected people. In this way, a social distance for avoiding virus entry into the respiratory system is critical $[32,33]$.

Cell-based therapy is one of the fast-growing classes of therapeutics during this pandemic. Concurrent with the spreading of COVID-19 worldwide, USA, China, Jordan, Iran, and several other countries began cell-based therapy clinical studies for treating COVID-19 patients with acute respiratory distress. Few studies have been published and reported that clinical trials were approved for starting phase II and III [1, 34]. Several cell-based therapies have steadily focused on successfully treating of patients induced by coronavirus, such as intravenous (IV) injection of stem cells and immune cells.

One novel aspect of this study focuses on the potential application of personalized medicine (PM) in treating severe cases of COVID-19. However, it is theoretical, as any realworld examples of the use of genuinely personalized medicine have not existed yet. By contrast, there are prestigious pieces of evidence that demonstrate the immunomodulatory effect and banking potency of MSCs for future application in
Personalized Medicine. This theory has been conjugated with some evidence that we review in the present study. Besides, we discuss the importance of PM and its possible aspects in COVID-19 treatment; and then review the cell-based therapy studies for COVID-19 with a particular focus on stem cellbased therapies as a primary PM (Fig. 1).

\section{Personalized medicine and its importance in COVID-19 treatment}

Personalized medicine is known as advanced health services administration methods to patients live in different geographical regions with emerging data based on molecular and genomic information. During this pandemic, several new therapeutics and management of the disease have been developed. However, the clinical symptoms and consequence response to drug treatments can significantly vary from one patient to the next [24]. The variations in response to drugs and treatment failures are related to several factors: the health status of the body, genetic and environmental factors, the amount of virus in the body, and variations in the pharmacokinetics of drugs in everybody. In this view, personalized management is crucial to identify candidate patients with superior target reactivity and the effective treatment for an individual patient and the national difference. Recently, general principles of PM, including genomics and proteomics, have provided new viewpoints for treatment and prevention of disease and increased our understanding of each patient's best treatment in clinical practice [23]. The main concepts of PM are the integration and collaboration of interdisciplinary sciences, including genomics, immunology, pharmacology, virology, laboratory sciences, molecular pathology, molecular and cellular biology, regenerative medicine and cell-based therapies, biotechnology, nutrition, lifestyle and environmental factors, epidemiology, nanotechnology, and bioinformatics that can be influenced on the response and management of the disease for each person. These multidisciplinary collaborations play a crucial role in designing and advancing therapeutics and effective vaccines to inhibit COVID-19, which has spread throughout the world [35]. This strategy can create an instant global teamwork connection to improve overall health care and better monitor the response to medical interventions in COVID-19 patients. The multidisciplinary collaborations have been summarized in Fig. 2.

Genetic alterations in COVID19 patients can increase the risk of a virus attack, high concentration of virus in cells, and finally, ARDS, organ damage, or death [36]. It can explain why some patients fare worse than others with the same condition even if they take the same drugs or clinical medication. Despite the widespread use and proven efficacy of antiviral drugs, there are many reasons why some affected individuals with COVID19 are not treated with available antivirals. Typing and genetic 
Fig. 1 The strategy of cell therapy and personalized medicine

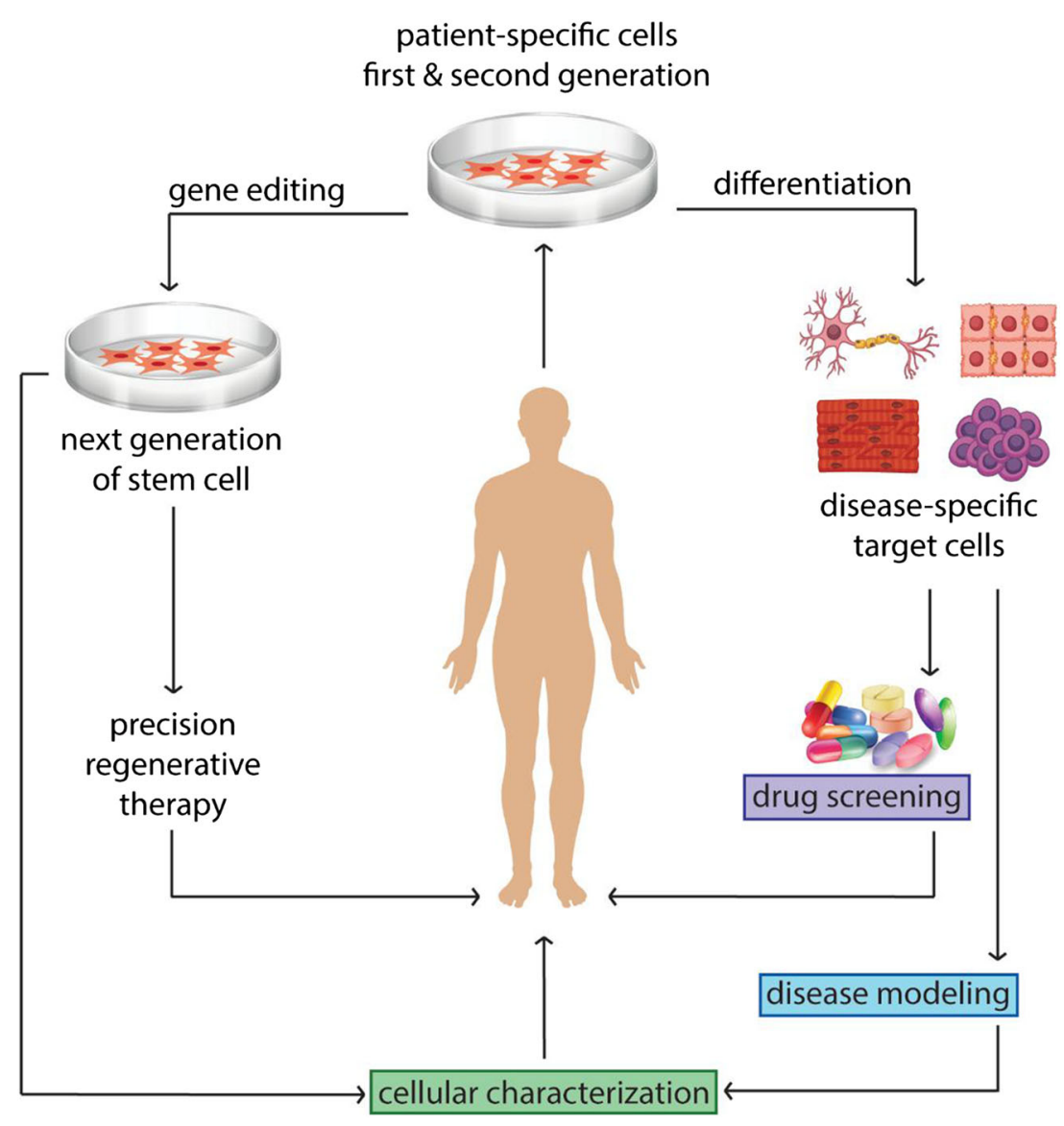

polymorphisms in the genome of an individual associated with the response to antiviral drugs such as virus invasion inhibitors, anti-hypoxic, anti-septic shock, anti-secondary infection, viral toxicity and sensitizers, angiotensin-converting enzyme (ACE) inhibitors, and angiotensin antagonists which have been identified by single-cell RNA sequencing (scRNA-seq) [36]. Cytochrome oxidase 450 (CYP450), a critical enzyme in the genome of mitochondrial, plays a vital role in drug metabolisms. Genetic variations and polymorphisms in the CYP450 can influence the amount and speed of drug metabolisms. Individuals with point mutation and different polymorphisms in CYP450 could have low or high levels of response to antiviral drugs, which is an essential factor for the development or suppression of infection. Data from some studies suggested that CYP450 enzymes, especially CYP3A4 and CYP3A5, have a potential role in response to ribavirin, $\alpha$-interferon, chloroquine, and lopinavir drugs [37].

Although genetic similarity is seen in the family, different responses to medical care and drugs, or different symptoms from asymptomatic to severe, can be observed in individuals in the family [38]. Apart from the complexity of the virus, the level of cytokine expression and immune response to the secretion of antibodies and macrophages are different in individuals in every disease. Also, we have introduced the role of
Fig. 2 The multidisciplinary collaborations for personalized medicine of coronavirus infection

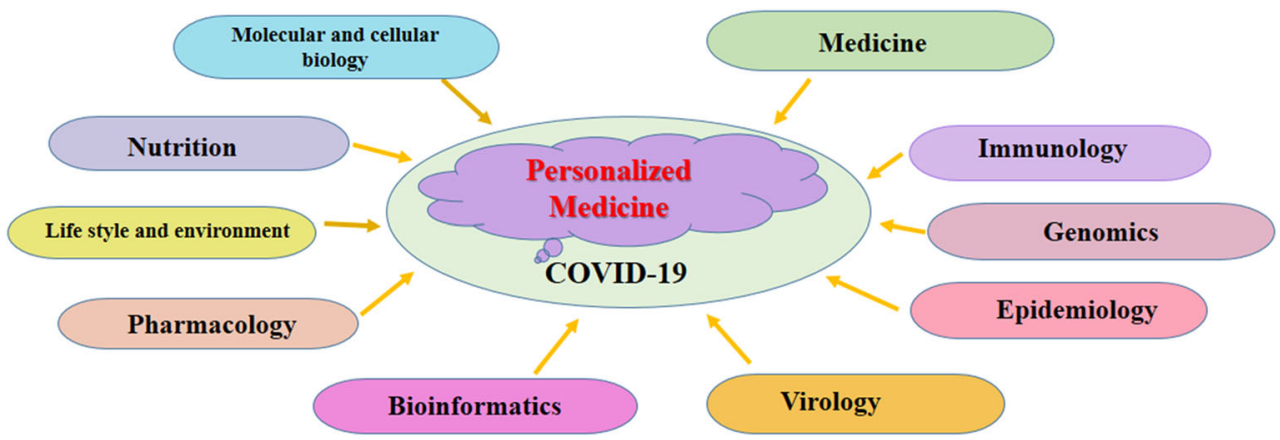


polymorphism in interleukin-4, interleukin-17, and interferongamma in protective effects or increasing the risk of tuberculosis in our previous study [39]. Genetic variations influence the intensity of cytokine storms too. A cytokine storm is a high overreaction of the immune system that can cause massive inflammation [37]. The number of infected cases and the mortality rate of COVID-19 have been reported differently in various countries due to genome variations in drug responses in medical care. Although the mortality rate in adults above 65 is high, the assessment of multiple reports has shown the high rate of mortality in young people with ideal BMI and athletes. The mortality rate in the USA and Europe is more than in Asia and the African region. We have noticed in our previous study about this [38].

\section{Approaches of Personalized Medicine and its Current Candidate Treatments for COVID-19}

Different studies have revealed that SARS-CoV-2 can cause various clinical manifestations among various groups of patients. Also, different people respond differently to the common treatment of this disease [40]. In this view, some risk factors which are associated with weaker prognosis and the higher chance of developing the severe or critical form of coronavirus disease of 2019 (COVID-19) are pregnancy [41], pre-existing underlying diseases including cardiovascular disorders, diabetes, and hypertension [42, 43], being old [43], belonging to some racial groups including black, Asians or minority ethnics [44], lacking anti A antibody in serum [45], having the Body Mass Index (BMI) higher than 30 [46] and cigarette smoking [47]. A case defines as severe when the patient's respiration rate is higher than 30 per minute, and the oxygen saturation is lower than $93 \%$, or the ratio of arterial oxygen partial pressure to fractional inspired oxygen $(\mathrm{PaO} 2 / \mathrm{FiO} 2$ ratio) is lower than $300 \mathrm{mmHg}$ [48]. Similarly, a case describes as critical when the patient develops respiratory failure, which indicates respiratory intubation. The patient is in septic shock or has any other organ failures, requiring admission in an intensive care unit (ICU) [48].

Given that SARS-CoV-2 binds to ACE-2 existing on a large number of cells, including alveolar and cardiac cells, to enter them and to cause infection [49], the presence of different variants of this receptor enzyme, like S19P, I21T/V in each individual could be one of the reasons for various manifestations among COVID-19 patients [50]. Moreover, according to studies, cytokine release syndrome (CRS), which is defined as the release of inflammatory cytokines like interleukin 6 (IL6) in some COVID-19 patients, is significantly associated with the severity of this disease $[51,52]$. In this regard, Wan et al. have found that cluster of differentiation 4 (CD4+), cluster of differentiation 8 (CD8+) cells, IL 10, IL6, and pulmonary inflammation index (PII) can be used as prognostic factors in patients with COVID-19, which can justify the abovementioned different responses to standard therapies in these individuals [51]. Furthermore, a study conducted by Chen et al. has been demonstrated that severe cases of COVID-19 have higher levels of ferritin, $\mathrm{C}$ reactive protein, lactate dehydrogenase, ALT, AST, and D-dimer in addition to the cytokines including IL6, IL10, tumor necrosis factor-alpha (TNFalpha) and IL2 receptor antagonist (IL-2RA) [53]. Additionally, the decrease in platelet count and having the genetic profile of sickle cell trait can have very high prognostic value in patients affected by SARS-CoV-2 [54].

Thus, the presence or absence of these factors, and probably many other factors, which have not been studied so far, can cause many common therapy results in COVID-19 patients. In this sense, PM, which aims to make a difference among different individuals based on their genetic profile or their other factors, to offer the most tailored therapy with the least side effects, could have many beneficiary results. Besides, PM could play critical roles in treating, diagnosing, screening, and preventing this worrying disease [55]. As an example, plasmid DNA and mRNA-based vaccines, which have created meaningful attentions and efforts because of their impressive potential as platform technologies, could be employed for a diversity of treatments ranging from PM to global health plans [56]. Moreover, based on studies, the possible treatment candidates of PM in COVID-19 patients may include injection of various type of stem cells, exosomes, and natural killer (NK) cells, using allogeneic cardiosphere-derived cells, screening of the effects of various antiviral therapies on patient own cells, providing the individual model of lung involvement and producing non-reject-able lung transplants. Furthermore, some of these genomic variations and cell metabolites, biomarkers, and small molecules have larger effects on the control of infected cells during replication, physiological and pathological processes, and signaling pathways of infectious with considering lifestyle conditions and dietary factors. In this regard, genomic information can extend PM and human genetic factors can expand the knowledge about the impact of drug response or appropriate drug dose for patient management according to diet habits and race-based.

\section{Cell-Based Therapies for COVID-19}

\section{Natural Killer Cells (N.K. Cells) Therapy}

Natural killer cells are considered part of the innate immune system, which has significant roles in targeting tumor cells and defending the body against bacterial and viral pathogens [57]. So far, the application of natural killer cells has indicated promising results as a treatment in patients suffering from cancer or patients infected with some viral pathogens [58]. From this view, it has the potential to be more invested in 
treating patients with COVID-19. These cells have a critical function in bridging innate and adaptive immunities [59]. After viral infections, the host cells display more responsive to N.K. cells and happen manner through (I) Upregulation of self-encoded biofactors by infection or cellular stress; (II) Downregulation of ligands for inhibitory receptors which suppress these cells activation, and (III) Direct identification of viral components [60]. However, the exact mechanisms require to locate their proper functions during different challenges, restraining of the damage is inadequately comprehended [61]. Recently, Novocellbio (Incheon, South Korea) reported assuring NOVO-NK results, an autologous N.K. cell therapy product, in laboratory and animal studies against SARS-CoV-2 infection [62]. To date, five clinical trials also have been registered in the United States National Library of Medicine at the NIH (clinicaltrial.gov) to assess the immunogenicity and safety of obtained peripheral blood mononuclear cell (PBMCs)-derived N.K. cells from healthful donors in the treatment of COVID-19 patients [59].

\section{Allogeneic Cardiosphere-Derived Cells (CAP-1002)}

Cardiosphere derived cells (CDCs) are cardiac progenitor cells, which can regenerate heart tissue and be used in several cardiac diseases [63]. Given that SARS-CoV-2 can attack cardiac cells and lead to serious cardiovascular complications [42], the application of CAP-1002 can be considered as a candidate treatment in these patients. As Singh et al. have shown in a case series that the administration of CAP-1002 in 6 critically ill patients with COVID-19 has led to considerable improvements in their manifestations, including weaning from respiratory support in 4 patients, decreasing ferritin level in 5 ones, and increasing in the absolute lymphocyte count in 3 of them; generally, it resulted in the resolution of critical manifestations in 4 of these 6 patients [64]. Besides, it caused no detected side effects in the investigated patients [64]. This promising study was conducted in the initial phase and demonstrated the visible safety of CAP-1002 in COVID-19; however, further research with more efficient sample sizes is needed to elucidate the effects of CAP-1002 on COVID-19 patients.

\section{Exosomes}

A wide range of stable molecular biomarkers such as microRNAs (small molecules with 21-23 nucleotides), lncRNA (large non-coding molecules with 60-210 nucleotides) in whole blood, cerebrospinal fluid (CSF), plasma, and other biofluids were identified as a potential indicator of prognosis and early diagnosis of a disease. According to the definition, exosomes are 40-150 nm extracellular vesicles (E.V.), which are secreted from many cell resources such as stem cells, and they play a critical role in communication between cells through transferring proteins, RNAs, and bioactive lipids [65]. These stem cell-derived exosomes are the small packets containing cellular proteins and nucleic acid materials such as mRNA and miRNA produced by different stem cells. Some biomolecules can be accumulated into exosomes that are regularly released from the blood. The role of exosomes as a vesicle to secrete and store biological molecules is crucial [66]. Hence, MSC-secreted exosomes have been increasingly recognized as a multicomplex paracrine factor that carries different biomolecules, for instance, a series of uncoded miRNAs like miR-34a, miR-200b/c, miR-146a, and Let-7 which are classified via their interaction with proinflammatory mediators. The introductory research described the efficacy as well as safety of MSCs-derived exosomes in relieving signs of COVID-19. There are research which proved post-exosomal infusion, the related cytokine storm, and proinflammatory signaling biomolecules are significantly decreased, which frequently are responsible for ARDS pathogenesis $[67,68]$. Different studies have demonstrated that the exosomes could improve anti-inflammatory signaling factors which can minimize the intensity of the injuries to the lung by developing permeability and applicational characters of the alveolar epithelium [69-71]. Based on the results, the exchange of air (which contains high level of oxygen) is facilitated [67]. Extra deep-diving into the same, exosomes' capacity to transfer mitochondria to alveolar cells more improved their survival, consequently improved cellular regeneration. Such impacts have paved the way for the therapeutic value of this cell-free pharmaceutical approach. Apart from their impacts on the preclinical ARDS model, MSC-derived exosomes also contribute to direct inhibition of viral replication $[67,71]$.Y in and colleagues have shown that the injection of MSC-derived exosomes has several advantages over parent MSCs. MSC-derived exosomes are cell-free therapy and have a lower risk of immunogenicity, tumor formation, and pulmonary embolism than the parent MSCs. Besides, they can cross the blood-brain-barrier, a property that makes them a suitable choice in some neurological diseases [72]. Furthermore, the study conducted by Khatri et al. has indicated that exosomes could inhibit the hemagglutination ability of different influenza viruses, including the avian, swine, and human influenza viruses, and therefore have substantial roles in inhibiting the replication of these viruses and their apoptotic effects on the alveolar cells [73]. Moreover, in this study, the anti-influenza effect of MSC-EV has been attributed to its RNAs component. However, the pre-incubation of MSC-EV with RNase has not led to any anti-influenza effect [73]. The BM-MSCs derived exosomes, a complicated mix of signaling nano-vesicles, are novel, multifunctional, and new biologic factors that can be the primary clue to down-regulating cytokine storms and convert the repression of defense system of the host which is special to COVID-19 [74].

Furthermore, in another study, the positive impacts of MSC-EV on pulmonary inflammation has been reported 
[75]. Recently in a nonrandomized open-label cohort clinical research, exosomes obtained from allogeneic bone marrow MSCs (entitled ExoFlo ${ }^{\mathrm{TM}}$ ) were assessed in 24 cases with severe coronavirus infection as possible therapeutic agents [74]. In the present research, both efficacy and safety of ExoFlo $^{\mathrm{TM}}$ were practically confirmed, but further studies are required to find out its curative capacity, particularly randomized trials. However, according to the safety profile, clinical and paraclinical criteria in severe COVID-19 patients, ExoFlo ${ }^{\mathrm{TM}}$ may be a hopeful potential treatment for this disease [74]. Based on the literature review and registered clinical trials, we found three trials that have used MSCs derivedexosome by tow route aerosols and intravenous. Some studies support the value of MSC- derived secretome as a suitable cell-free therapeutic option for those infected with the coronavirus $[59,76]$. Our literature review demonstrates that exosomes can be an attractive treatment choice for COVID19 patients.

\section{Treatment Using Stem Cells}

Using cells to treat patients, particularly stem cells, many opportunities exist for clinicians to contribute to PM (Fig. 3). Stem cells acquire from different sources and can be differentiated into diverse cell types (Fig. 4). Since the beginning of this pandemic, some stem cell researchers have offered MSC therapy as an alternative hopeful treatment for this novel disease [77]. However, this novel treatment, compared with other treatments, is in the infantile stages; stem cells are one of PM's primary arms. We will describe stem cell-based therapy as a precision therapeutic candidate for COVID-19 treatment in detail in the following sections.

\section{Stem Cells and Personalized Medicine}

Nowadays, cell therapy is one of the developing treatment strategies for a wide range of diseases, and also infections such as HIV and new appeared one named COVID19. Cell-based therapeutics play a potential role in providing an immediate promising treatment option while there are no effective drugs and specific vaccines.

Various types of stem cells with the ability of regeneration, differentiation capacity, and cytokine release can have potential use in the context of cell therapy. In summary, these cells have been classified into two generations based on clinical use [78]. The first generation includes multipotent somatic stem cells containing three groups. The first group is hematopoietic stem cells (HSCs) with over 60 years of clinical treatments [79]. The second one is the mesenchymal stem/stromal cells (MSCs) originated from various tissues (e.g. bone marrow, adipose, umbilical cord, and others) [80] with unique features in immunomodulation, anti-inflammation, angiogenicity, and anti-apoptosis. They used clinically over 20 years ago for the first time [81]. The other is fetal tissue-derived stem cells with limitations in number and also ethical concerns [82]. Another generation has arisen by using pluripotent stem cells (PSCs)
Fig. 3 The personalized cellbased therapy strategies in COVID-19 treatment; The figure is made with biorender (https:// biorender.com/)

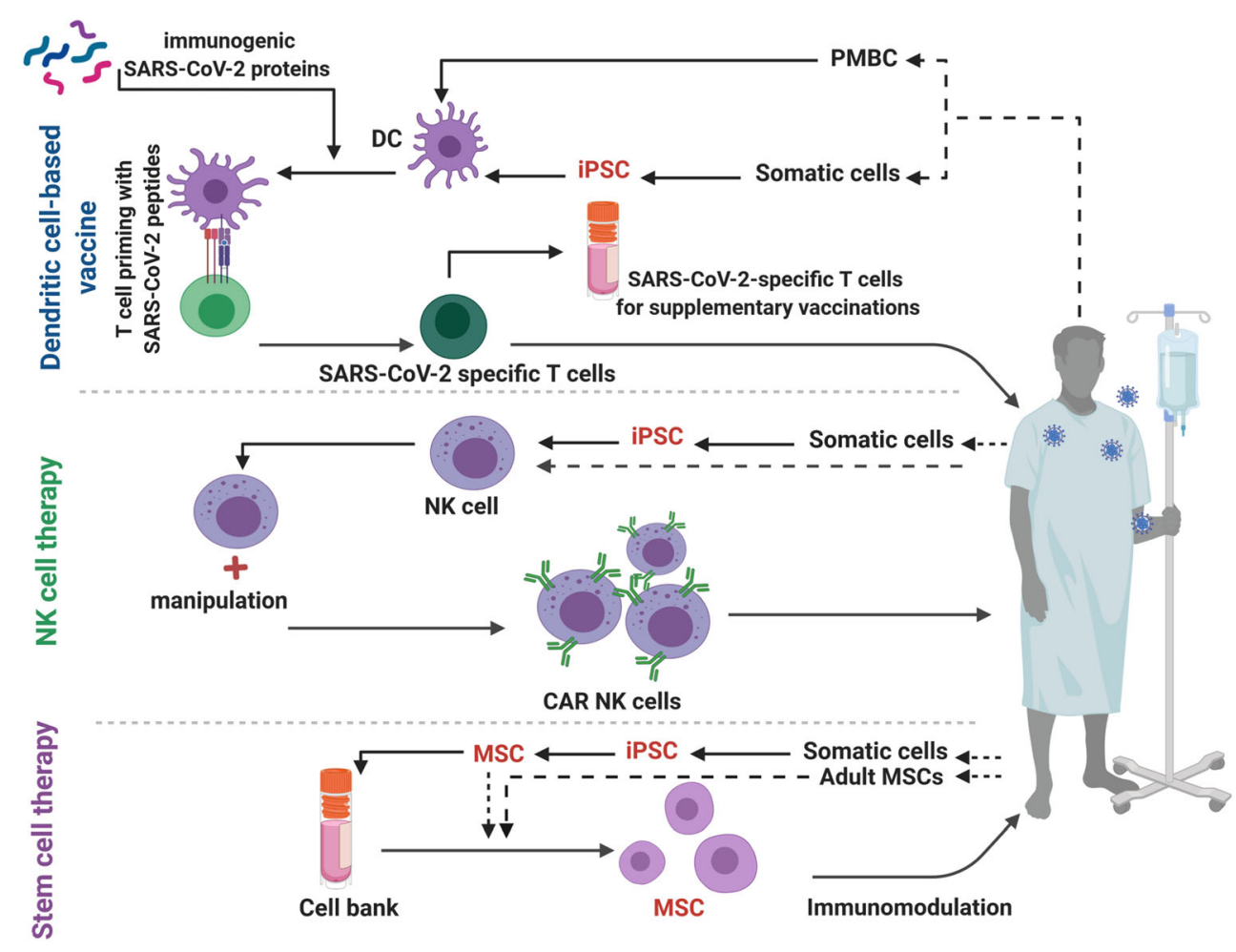


Fig. 4 First-generation stem cell types, including adult stem cells and fetal membrane-derived stem cells, demonstrated feasibility and safety; however, they were heterogeneous results and low efficiency in the clinical application. To resolve some limitations, second-generation stem cells suggest the advantage of pluripotent stem cells, including embryonic stem cells and induced pluripotent stem cells. Nextgeneration of stem cells for the enhancement of stem cell therapy is directed toward cell engineering

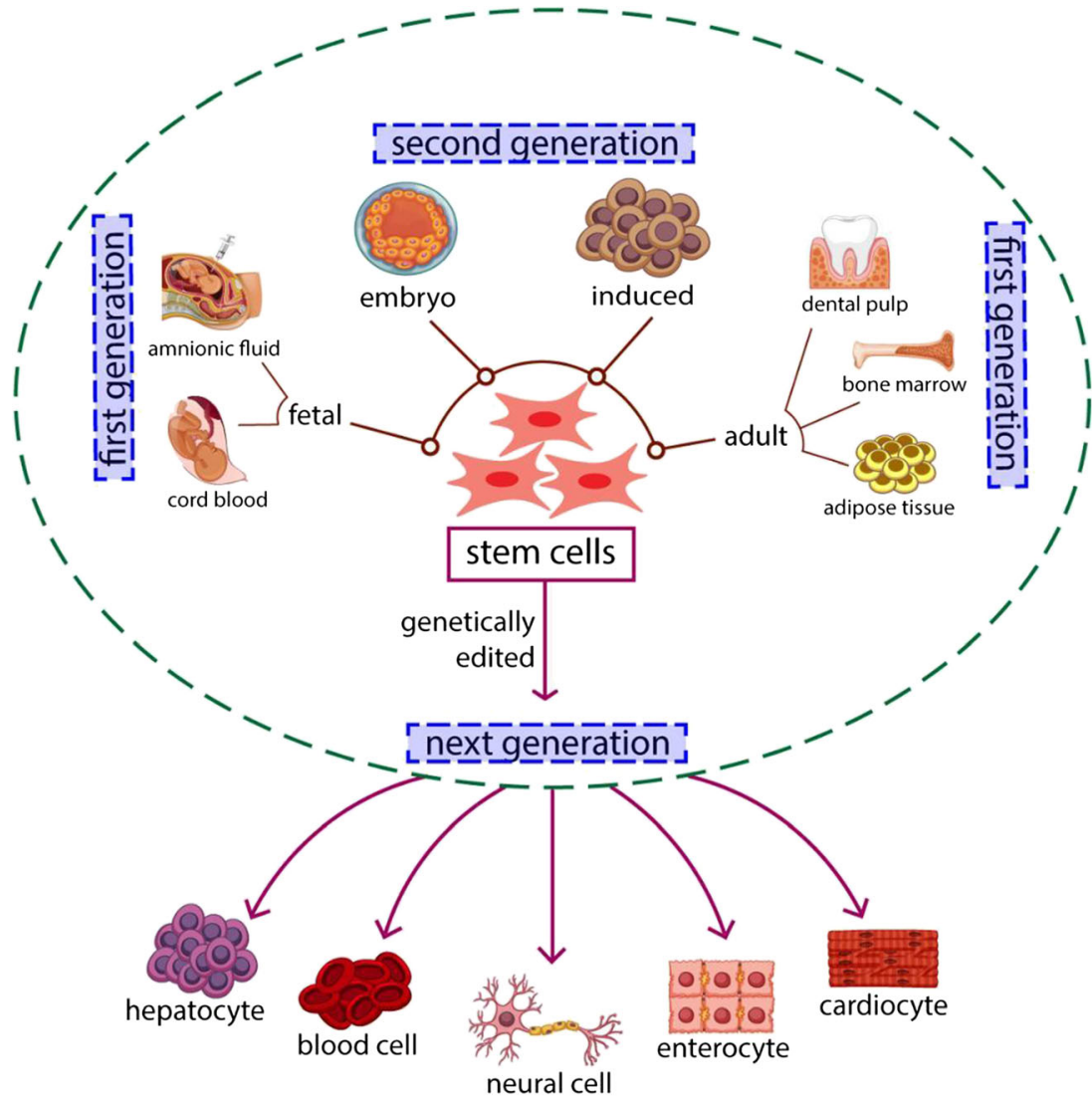

with ideally in vitro expansion properties and differentiation potential into different types of body cells [83]. They include human embryonic stem cells (hESCs) [84] and induced pluripotent stem cells (iPSCs), which were used in clinical trials 5 to 10 years ago [85]. There are genetic instability concerns and immune rejection due to allogenicity and ethical issues for ESCs [86]. Stem cells can utilize in PM with the aim of custom-tailor treatments based on individual genetic properties. Stem cells are listed as autologous stem cells from the first-generation including those derived from bone marrow (B.M.; HSC and MSC), adipose tissue (AT; MSCs), cord blood (C.B.; HSC), and cord tissue (C.T.; HSC and MSC) and also iPSCs from second generation [87]. The cell sources and COVID-19 related studies have been explained in the next section.

\section{Multipotent Somatic Stem Cells}

Multipotent somatic stem cells or adult stem cells that can find throughout the body of everyone can renew and differentiate into all the cell types of their origin organ [88]. Among these stem cells, HSCs and MSCs are mostly used-sources intended for cell therapy [87]. In precision medicine, the best useful stem cell sources are autologous ones. The relevant sources of autologous stem cells have been C.B., CT, B.M., and AT. C.B. and C.T. are waste products of accouchement and readily available. C.B. contains HSCs, and C.T. primarily includes MSCs, which are limited in number and required in vitro expansion before their use [87].

B.M. can be a source of both HSC and MSC and is utilized in many clinical and preclinical investigations to treat different diseases $[89,90]$. On the other hand, BM-MSCs have some drawbacks in older donors such as decreasing numbers, proliferation and differentiation capacity, angiogenic and wound healing features, and increased apoptotic and senescent properties along with invasive acquisition process [91, 92]. Although BMMSCs have shown the potential to be differentiated into mesenchymal (adipocytes, osteoblasts, chondrocytes, and muscles) and non-mesenchymal(neurons) cell types [93-95], it is not an ideal source of MSCs due to its mentioned limitations. AT-MSCs are close to BM-MSCs in etiology and functionality [35]; Furthermore, they can expand efficiently and be stable in culture for a long time [96]. Also, there are easy ways to access large volumes in any period of life. Although AT-MSCs have lower proliferation potential than CT-MSCs, easy accessibility along with lots of MSC numbers make AT the most useful source of MSCs for clinical applications [87]. MSCs are adult stem cells considered immune-privileged cells, mainly because of their lower level of expression of class II major histocompatibility complex (MHC-II) on their surface [97].

In addition to their regenerating potential, their immune regulatory aspects have recently attracted so much attention 
that several studies are conducted, investigating this feature as a valuable therapeutic option in different inflammatory disorders [1]. The process by which they affect immune response is multifaceted and includes direct cell to cell interaction and some paracrine factors such as exosomes [98]. These properties are eye-catching concerning CRS (cytokine release syndrome) treatment and its manifestations in COVID-19 patients. In the following section, the potential of MSCs in treating cases infected with coronavirus is reviewed in detail. Furthermore, MSCs frequently have been used in clinical trials of some viral infections such as Influenza, Hepatitis, and Human immunodeficiency virus (HIV).

\section{MSCs and COVID-19 Treatment}

MSCs has a significant on modulation of inflammatory progress as well as damaged cell repair [99]. Also, stimulation of MSCs by inflammatory cytokines (e.g. tumor necrosis factor (TNF) and interleukin-1 (IL-1)), can modulate immunosuppression process [100]. MSCs initially respond to inflammatory cytokines, so they release factors that regulate the immune system, which results in adjusting inflammation process. For instance, a significant amount of nitric oxide (NO) in mice, and indoleamine 2,3-dioxygenase (IDO) in humans, and chemokines released by MSCs present a central role in MSCmediated immunomodulation [101]. Moreover, MSC secretomes such as tumor-specific glycoprotein (TSG6) and hepatocyte growth factor (HGF) have been efficiently employed to treat some immune diseases [102]. Several principal factors that can affect the function of MSCs are cytokines, chemokines, growth factors, and Exosomes. MSCs can increase angiogenesis and display antifibrotic, antiinflammatory, and antioxidant outcomes [103]. MSCs immunomodulation or immunosuppression properties increase when the host has a hyperactive inflammatory situation. Other immunity aspects of MSC therapy, including induction of antiinflammatory macrophages, regulation of $\mathrm{T}$ and $\mathrm{B}$ cells, and dendritic cells, have been described [103, 104] (See Fig. 5). Advantages of MSCbased therapy are including:

- Accessibility in isolation from different tissues, such as bone marrow (B.M., most preferred site), peripheral blood (P.B.), adipose tissues (AT), Oral tissues, and Menstrual blood. These cells can be separated efficiently from neonatal birth-associated tissues, including placenta (P.L.), umbilical cord (U.C.: Wharton's jelly (W.J.) and cord blood (C.B.)), amniotic membrane (AM)/fluid (A.F.). Also, once separated, these cells can be maintained for further interventions;

- These cells are multipotent stem cells which can selfrenew by dividing and can differentiate into multiple specialized cells;
- MSCs can promptly grow to large-scale volumes in a relatively shorter period and can be deposited for repetitive curative interventions;

- So far, MSC-based clinical trials of MSCs didn't show any intense negative body reactions to allogeneic MSC;

- Several clinical trial studies mentioned safety of MSCs [1, $105,106]$.

MSCs can influence both adaptive and innate immune cells. MSCs may influence secretion of keratinocyte growth factor (KGF), prostaglandin E2, granulocyte-macrophage colony-stimulating factor (GCSF), IL-6, and IL-13 to promote phagocytosis and interaction of alveolar macrophage, alter the cytokine secretion profile of dendritic cell subsets and reduce the secretion of interferon $\gamma$ from natural killer cells. IL-10, transforming growth factor $\beta$ (TGF $\beta$ ), and tryptophan catabolizing enzyme indoleamine 2,3-dioxygenase secreted from MSCs can also repress $T$ cells' growth exchange the cytokine expression profile of $\mathrm{T}$ cell subsets [107]. Furthermore, the proliferation, differentiation, and chemotactic properties of B cells were impaired by MSCs [108]. Aside from its influences over the immune system, MSCs is capable of increasing the rebuilding the capillary barrier [109], ceasing bacterial growth [110], and reinstating alveolar ATP [111].

It was hypothesized that MSCs could improve acute lung damage and control the cell-mediated inflammatory response stimulated by coronavirus. In addition, MSCs are resistant to infection, and they lack the ACE2 that coronavirus applies for entering the cell $[112,113]$. Hence, MSCs can enhance the number of lymphocytes as well as regulatory D.C.s to boost their antiviral property, that lead into a reduced C-reactive protein and proinflammatory cytokines levels (IL-6, TNF $\alpha$, IL-8, etc.) in COVID-19 patient. These markers have a key role in inflammation and ROS to decline the oxidative stress and inflammation. Further, MSCs is capable of rising the IL10 level as an antiinflammatory protein which stimulates regulatory cells (e.g. Tregs) [1, 114]. Hence, MSCs are of crucial importance for immune homeostasis by associating with cytokines, chemokines, and cell surface molecules. Conclusively, all these immunomodulatory characteristics provide considerable potential for MSCs in clinical therapies. Hence, MSCs can be shown themself positive effects in the severe stage of COVID-19 pathology and generate several immune interactions with released cytokines and cell-cell contacts. The above factors are beneficial for COVID-19-induced ARDS (See Fig. 5).

\section{MSCs and Immune Activity}

MSCs can influence several immune cells, live B and T cells, dendritic cells (D.C.s), natural killer (NK) cells, neutrophils, and macrophages [115]. These specific modulators include 


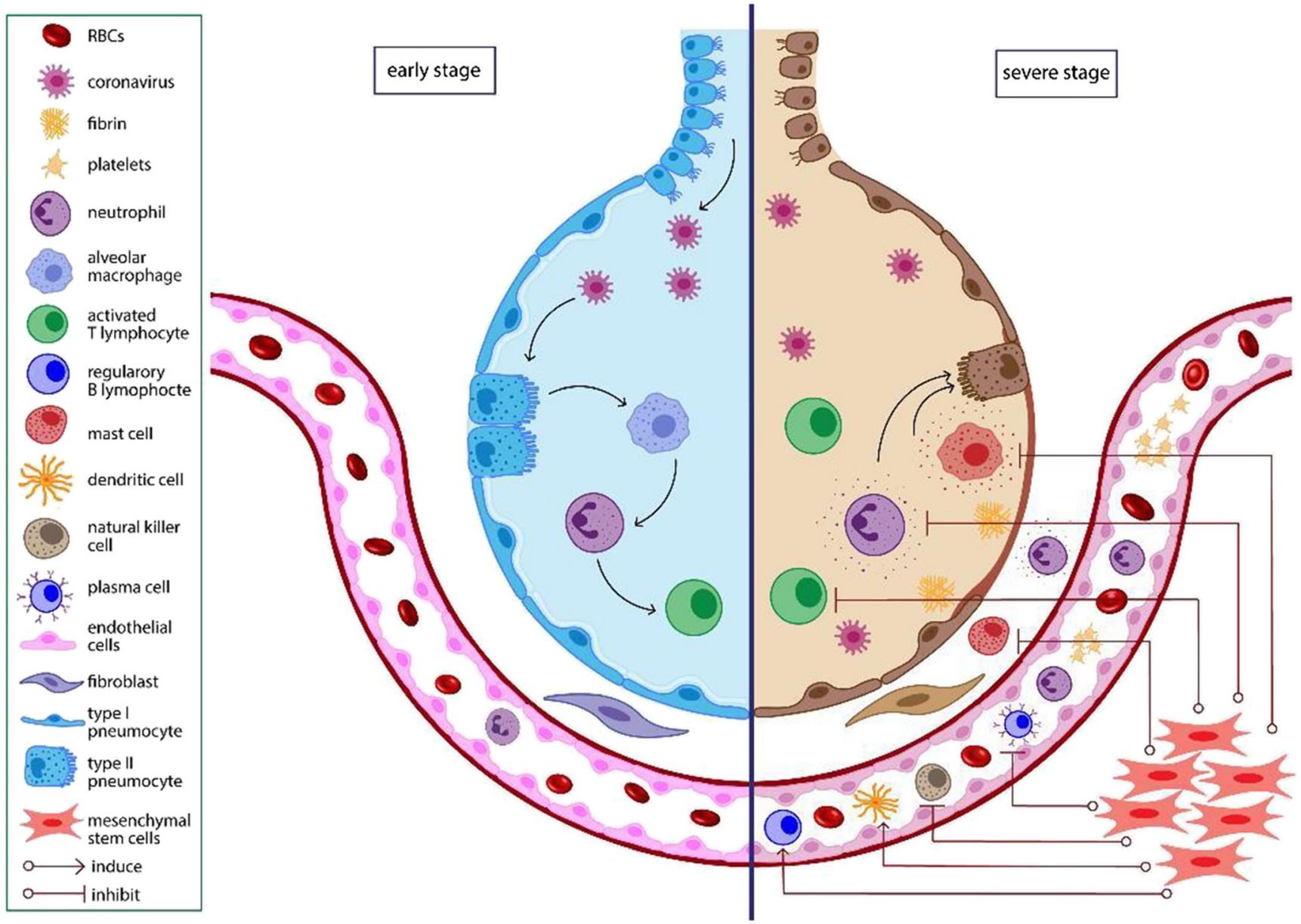

Fig. 5 Considered mechanisms of action of MSC function against respiratory inflammation caused by COVID-19. MSCs can be shown

their positive effects on inhibiting the severe stage of COVID-19 by releasing cytokines and creating cell-cell interactions

immune-modulatory factors, cytokines, growth factors, modulate inflammatory responses, and immune balance profiles [116]. Particularly, soluble immune secretomes, including prostaglandin E2 (PGE-2), indoleamine 2,3-dioxygenase (IDO), or nitric oxide (NO), react to immune cells to sstimulate immunoregulation by MSCs [117]. Function of MSCs in mediating different parts of the immune system (either innate or adaptive) provided in Fig. 6:

\section{- Innate immune systems}

D.C.s: Inhibition of D.C. movement, activation, separation, evolve, and endocytosis, N.K. cell: Inhibition of N.K. cell movement, growth, differentiation, maturation, and activation.

Macrophage: Overall activation of M2 macrophage polarization; stimulating proliferation of M1 macrophage in a specific micro context.

- Adaptive immune systems:
T cell: Inhibition of T cell survival, proliferation, differentiation, evolve, and activation, while increasing the number of T-cells.

B cell: Inhibition of B cell proliferation, differentiation, evolve, chemotaxis, and activation [118].

Using MSCs as a therapeutic option for cases infected with coronavirus contains two parts. Primarily, MSCs can lodge in the pulmonary vascular bed after injection, release antiinflammatory mediators, and decline the cytokine storm induced by a viral infection [119]. Next, MSCs can induce angiopoietin- 1 and KGF secretion, that are important for rebuilding alveolar-capillary barriers damaged by COVID-19 [120]. Also, MSCs have antiviral properties that exert this property in two ways: 1) the existence genes stimulate by IFN (ISG) which is capable of targeting at several phases of viral cycle, hence preventing viruses from trespassing cell membrane, blocking the endocytic route, mRNA transcription, nuclear import of mRNAs, genome integration/amplification, translation of protein, assembly of virus, and release. 2) By producing extracellular vesicles bearing antiviral microRNAs to the microenvironment such as miR-145, 


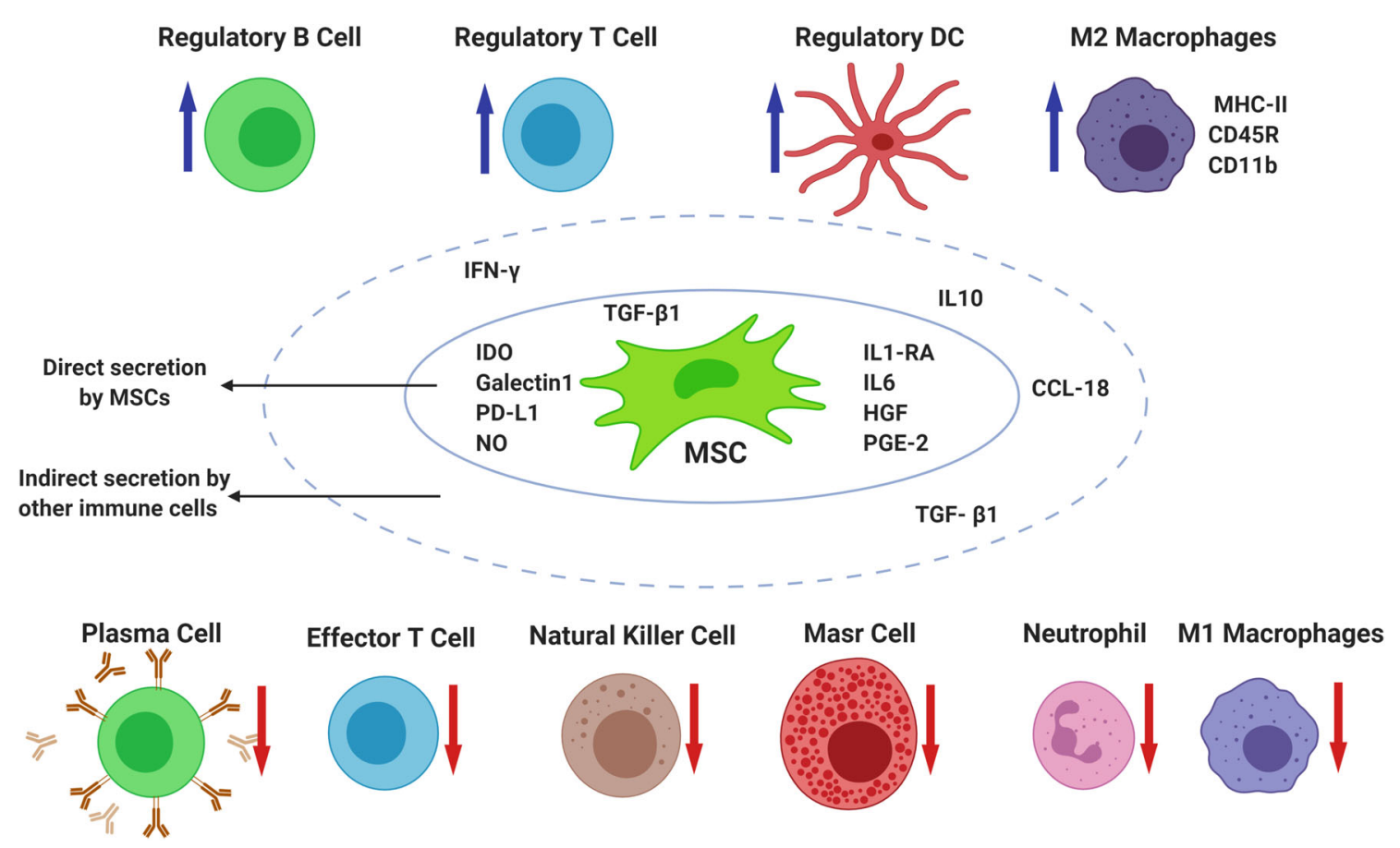

Fig. 6 The strategy of MSCs in interaction with host immune cells; The figure is made with biorender (https://biorender.com/) [1]

miR-199a, miR-221, and Let-7f [121]. Further, IFN $\gamma$ stimulated MSCs express IDO (Indoleamine 2,3dioxygenase), reducing intracellular Tryptophan content which may result in decreased viral proliferation [122].

\section{MSCs and COVID-19 Clinical Trials}

Currently, at least 60 MSC-based clinical trials for treating cases infected with coronavirus have been registered at the United States National Library of Medicine at the NIH (clinicaltrial.gov) (Fig. 7); however, several MSC-based clinical trials have been reported as well (Table 2). Recently, MSC therapy was reported in treating $\mathrm{H} 5 \mathrm{~N} 1$ viral infections that positively affect lung pathophysiology [126]. Subsequently, the preliminary case reports of clinical administering human umbilical cord MSCs (UC-MSCs) as a therapeutic approach for a COVID-19 positive 65-year-old woman came from China [124]. Based on the paraclinical analysis and C.T. images, this experiment demonstrated beneficial outcomes after three weeks of administering UC-MSCs [124]. After treatment with antiviral medicine like IFN- $\alpha$, lopinavir/ritonavir, and oseltamivir and Xuebijing injection, moxifloxacin, methylprednisolone, and immunoglobulin, the patient had an $87 \%$ increase in neutrophil and $9.8 \%$ decrease in lymphocyte. The patient has received cord MSCs and cord MSCs with $\alpha 1$ thymosin by weakening vital signs. Three times, $5 \times 10^{7}$ cells were treated at each injection. The study results demonstrated that serum albumin, CRP, ALT / AST piecemeal declined after the second injection and other vital signs cure.
Afterward, white blood cell count, such as neutrophils, declined to standard range, and the case was separated from mechanical ventilation device and could walk. Above all, $\mathrm{T}$ cells $(\mathrm{CD} 3+\mathrm{T}$ cell, CD4+ T cell, and CD8+ T cell) were considerably enhanced, and images of lungs C.T. scan showed that following the second and third injections of UC-MSCs, the pneumonia was improved. In two days, the third injection, the patient was discharged from ICU, and many vital symptoms and laboratory variables were normal. In the present study, data revealed that injection of umbilical cord mesenchymal stem cells is one of the best treatments for COVID-19, which may be used solely or with other stimulators of the immune system [124]. Another study was recently carried out jointly in China and the United States [127]. Seven cases of COVID-19 pneumonia in YouAn Hospital (located in the Capital of China) tolerated MSC transplantation and clinical advent from January 23 to February 16., improved immune functions [127]. Inflammation was evaluated two weeks after transplantation, and the findings illustrated that two days after MSC transplantation, all patients' clinical symptoms improved significantly [127]. One of the patients had acute conditions, and two of them had a better status were discharged in 10 days after transplantation. Based on the findings, stimulated cytokine-secreting immune cells, like CXCR3 $3+\mathrm{CD}^{+} \mathrm{T}$ cells, $\mathrm{CXCR}^{+} \mathrm{CD}^{+} \mathrm{T}$ cells, and peripheral lymphocyte, were enhanced as well as $\mathrm{NK} \mathrm{CXCR3}^{+}$cells disappeared on day 6. Also, the number of $\mathrm{CD} 14^{+} \mathrm{CD} 11 \mathrm{c}^{+} \mathrm{CD} 11 \mathrm{~b}$ mid regulatory D.C. cells enhanced significantly, and, simultaneously, TNF- $\alpha$ levels declined considerably. Although IL-10 in patients treated with MSCs, in comparison to those who 
Table 2 the list of published stem cell-based clinical studies for COVID-19 treatment; hUCMSCs (Human umbilical cordMSCs), IV (intravenous), ATMSCs (Adipose tissue-MSCs), MB-MSCs (Menstrual bloodMSCs), BM-MSCs (Bone Marrow-MSCs)

\begin{tabular}{|c|c|c|c|c|c|}
\hline $\begin{array}{l}\text { Stem cell } \\
\text { sources }\end{array}$ & $\begin{array}{l}\text { Number } \\
\text { of } \\
\text { patients }\end{array}$ & Result & Conclusion & Country & Ref \\
\hline hUC-MSCs & 12 & $\begin{array}{l}\downarrow \text { C-reactive } \\
\quad \text { protein } \\
\downarrow \text { IL-6 } \\
\uparrow \text { Lymphocyte } \\
\downarrow \text { Lung } \\
\quad \text { inflammation } \\
\downarrow \text { Time to clinical } \\
\quad \text { improvement }\end{array}$ & $\begin{array}{l}\text { IV infusion of hUC-MSCs is a safe } \\
\text { and effective option for severe } \\
\text { COVID-19. }\end{array}$ & China & [123] \\
\hline ACE2- MSCs & 7 & $\begin{array}{l}\downarrow \text { C-reactive } \\
\quad \text { protein } \\
\downarrow \text { TNF- } \alpha \\
\uparrow I L-10 \\
\uparrow \text { Lymphocyte } \\
\downarrow \text { over activated } \\
\text { cytokine-- } \\
\text { secreting cells } \\
\uparrow \text { pulmonary } \\
\text { function }\end{array}$ & $\begin{array}{l}\text { IV transplantation of MSCs was } \\
\text { safe and effective for the } \\
\text { treatment of COVID-19 } \\
\text { pneumonia patients, particularly } \\
\text { for the patients in critically severe } \\
\text { conditions. }\end{array}$ & China & {$[21]$} \\
\hline AT-MSC & 13 & $\begin{array}{l}\quad \downarrow \text { C-reactive } \\
\quad \text { protein } \\
\downarrow \text { IL-6 } \\
\downarrow \text { ferritin } \\
\downarrow \text { LDH } \\
\uparrow \text { Lymphocyte } \\
\uparrow \text { clinical } \\
\quad \text { improvement }\end{array}$ & $\begin{array}{l}\text { AT-MSC transplantation in severe } \\
\text { COVID-19 pneumonia under } \\
\text { mechanical ventilation in a small } \\
\text { case series did not cause } \\
\text { significant adverse events. It was } \\
\text { followed by clinical and } \\
\text { biological improvement in most } \\
\text { patients. }\end{array}$ & Spain & {$[13]$} \\
\hline hUC-MSCs & 1 & $\begin{array}{l}\downarrow \text { Inflammation } \\
\text { symptom } \\
\text { Throat swabs test } \\
\text { reported } \\
\text { negative after } \\
4 \text { days. }\end{array}$ & $\begin{array}{l}\text { Results demonstrated the clinical } \\
\text { outcome and great tolerance of } \\
\text { allogeneic hUC-MSCs therapy. }\end{array}$ & China & [124] \\
\hline $\begin{array}{l}\text { Allogeneic } \\
\text { MB-MSCs }\end{array}$ & 2 & $\begin{array}{l}\downarrow \text { Fraction of } \\
\text { inspired O2 } \\
\downarrow \text { Bilateral lung } \\
\quad \text { exudate lesions }\end{array}$ & $\begin{array}{l}\text { MSC transplantation may consider } \\
\text { as an alternative approach for } \\
\text { treating COVID-19, especially in } \\
\text { patients with ARDS. }\end{array}$ & China & [125] \\
\hline $\begin{array}{l}\text { Exosomes } \\
\text { Derived } \\
\text { from } \\
\text { BM-MSCs } \\
(\text { ExoFlo } \\
\text { (MM) }\end{array}$ & 24 & $\begin{array}{l}\uparrow \text { Lymphocyte and } \\
\text { neutrophil count } \\
\downarrow \text { C-reactive } \\
\quad \text { protein } \\
\downarrow \amalg \mathrm{LL}-6 \\
\downarrow \text { ferritin }\end{array}$ & $\begin{array}{l}\text { This product is a promising } \\
\text { therapeutic candidate for severe } \\
\text { COVID- } 19 \text {. }\end{array}$ & USA & {$[27]$} \\
\hline
\end{tabular}

received usual treatments, was increased. Further, gene expression profiling of MSCs revealed that these cells are $\mathrm{ACE}^{-}$and TMPRSS2${ }^{-}$, that proved that MSCs have no infection [127]. Hence, the authors argued that UC-MSCs may be safe and efficient for patients with COVID-19, particularly those with severe disease.

In phase I of another clinical study, a parallel assigned controlled, nonrandomized trial was conducted to assess the safety of IV injection of UC-MSC in treating 18 cases with mild to severe infection of COVID-19 [128]. In this study, the treatment was carried out by three IV infusions of $3 \times 10^{7} \mathrm{UC}$ MSCs per each patient, in which, after treatment, all patients improved and were discharged. The results of this trial have demonstrated that IV infusions of UC-MSCs in moderate to severe COVID-19 patients were well-tolerated and safe [128]. In another clinical trial conducted in China on 12 patients with 

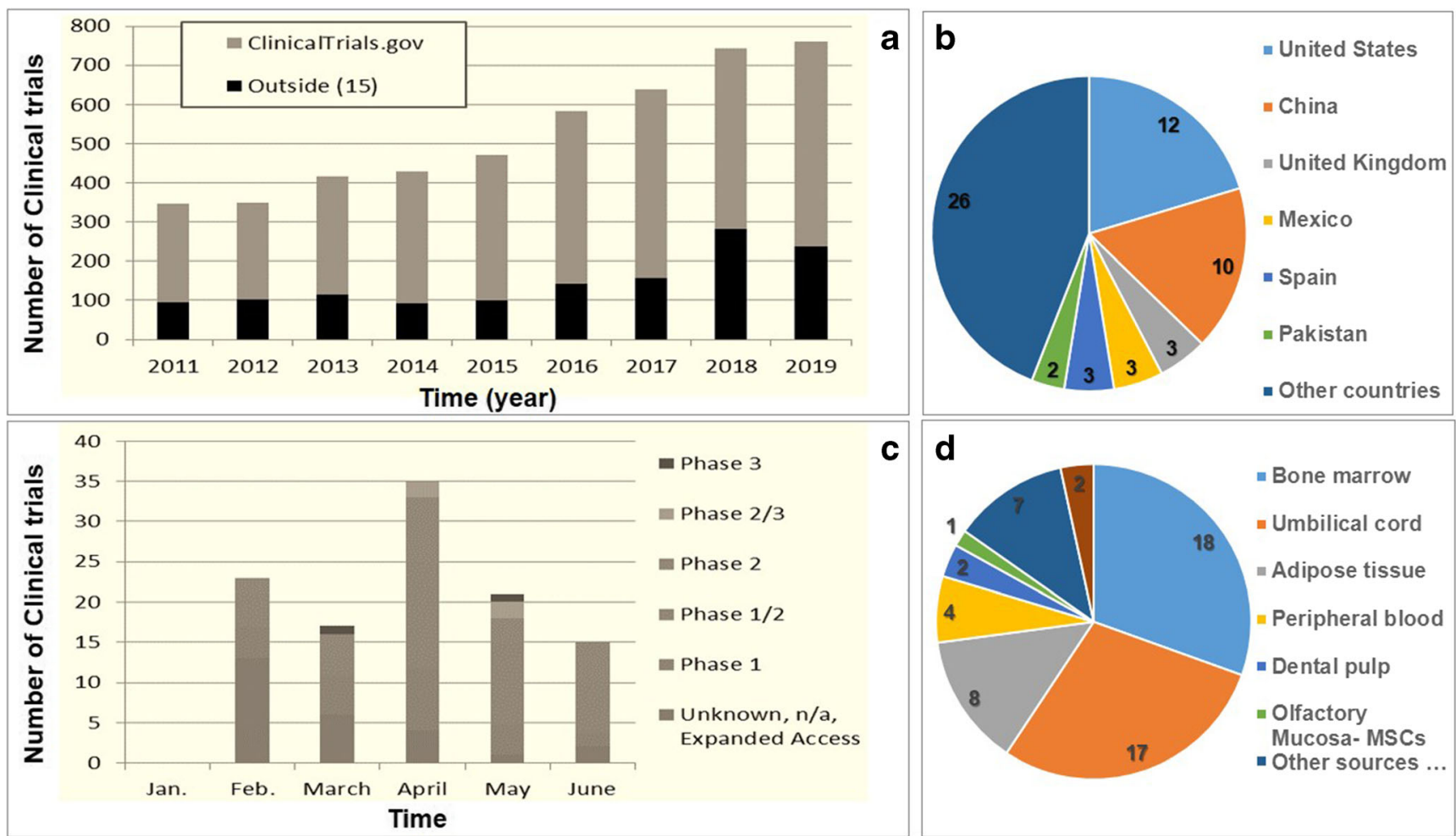

c

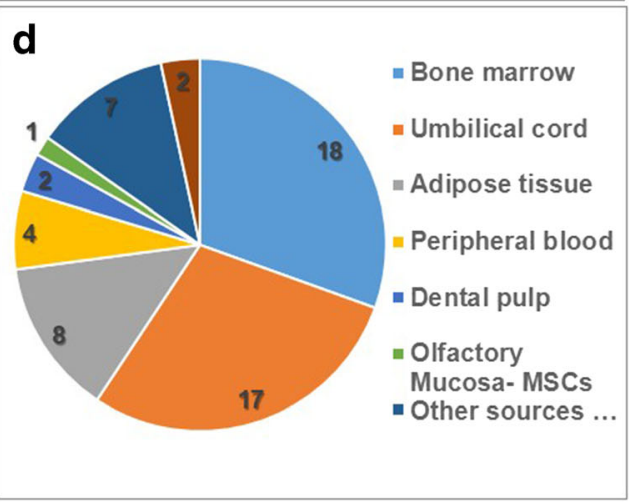

Fig. 7 Graphs have been obtained from the content of https:// clinicaltrials.gov/ and https://celltrials.org/; A: The histogram shows the total number of advanced cell therapy trials registered each year. B: Pie chart of the number of stem cell based-clinical trials for COVID-19 according to registered countries; the highest number of ongoing clinical trials respectively are in USA, China, United Kingdom; C: Bar chart

serious infection, IV transplantation of hUC-MSCs was reported as a secure and efficient approach that can be considered as a noninvasive treatment, helpful and preferred therapeutic approach for patients with severe COVID-19 [123].

PLX cell is a stem cell-based product in which an Israeli regenerative medicine company conducted its clinical study for treating six severely infected COVID 19 patients [129]. Pluristem Therapeutics Inc. as a prominent regenerative pharmaceutical firm declared that the FDA has released the Company's Investigational New Drug (IND) application for starting the second phase of clinical trial of PLX cells for treating 140 adult's infected with intense type of COVID-19 $[129,130]$. These cells are allogeneic mesenchymal-like cells that can stimulate the immune system's natural regulatory $\mathrm{T}$ cells and M2 macrophages. Hence, PLX cells can decrease occurrence andlor severity of the coronavirus infection [131]. According to a report on May 8, 2020, a company registered a phase II trial with FDA approval entitled "A Randomized, Double-Blind, Placebo-Controlled, Multicentre, and ParallelGroup Phase II Study to Evaluate the Efficacy and Safety of Intramuscular (I.M.) infusion of PLXPAD for the Treatment of severe COVID-19". The study described the treatment of 140 adult cases with intubation and severe pulmonary problems due to COVID-19. The study's primary outcome is included in the represents all cell-based therapy clinical trials for COVID-19, binned by number per month, and color-coded by trial phase. The decline of new trial registrations recommends that companies that were ready and able to compete in cell-based therapy for COVID-19 have previously entered the market; D: Pie chart of different sources of MSCs used in COVID-19 clinical trials

number of ventilator-free days during four weeks of the study [129]. The survival rate was $87.5 \%$, of which $75 \%$ of patients need no mechanical ventilation with a $62.5 \%$ discharge rate. Besides, recently, it was reported that Mesoblast's remestemcel-L (a stem cell-based product from regenerative medicine company Mesoblast) received FDA IND clearance for phase III of treating COVID-19 patients with ARDS [59]. Most clinical trials have declared the use of MSCs derived from the allogeneic umbilical cord, Wharton's jelly, bone marrow, adipose tissues, dental pulp, menstrual blood, companiesspecific products, and unknown sources. Furthermore, IV and I.M. cell transplantation routes were the commonly used methods in clinical trials.

\section{Induced Pluripotent Stem Cells}

For the first time, Yamanaka and colleagues indicated redesigning mouse fibroblasts into iPSCs by a package by 4 transcription factors in 2006 [132], followed by reprogramming of human somatic cells using similar factors in the next year $[132,133]$. iPSCs with self-renewal property and pluripotency (distinction capacity into all cell types of every three germ layers) are similar to ESCs. At the same time, they lack ethical issues and immunogenic problems of human ESC [134]. Developments in 
iPSC technology have shown that peripheral blood mononuclear cells (PBMCs) are preferred over fibroblasts as a primary cell source due to their less invasiveness, the small amount of sample (2-6 mL), and the ability to reprogramming immediately after sampling [135]. Therefore, PBMCs and fibroblasts have been commonly introduced for iPSCs production [98]. Three principal applications are considered for iPSCs, including disease modeling, drug screening and discovery, and regenerative therapy, all for PM [136]. Therefore, iPSC technology can provide treatment platforms based on individual genetic properties [136] and promote regeneration processes. Also, in organ transplantation with current limitations about lack of donors and its immunogenic problems, iPSCs can be offered as one of the best sources to make patient-specific organs with fewer problems after implantation [133]. Some pieces of evidence prove that the increased expression of decorin and lumican genes by iPSCs as they differentiate can begin to repress recruitment of endothelial cells in hosts [137]. However, differentiating iPSCs display the lack of pluripotency simultaneous with a concurrent rise in the expression of known tumor suppressors, particularly the ECM mentioned proteins [137]. Therefore, the issue forms a main considerable subject in iPSC using for lung alveolar tissue regeneration. Although, iPSCs may have teratoma formation issue like ESCs, it can be solved by deriving mature cells or tissues from iPSCs in order to be more practical in the clinic. However, this process takes a lot of time (4-6 months) and is high cost [87].

These pluripotent stem cells' ability to generate various patientspecific tissues has made them a unique choice for treating many diseases [138]. Given that in COVID-19 patients, the lung is one of the central targeted tissues, whose damage has critical impacts on patients' prognosis [139], the lung transplantation using iPSCs technology in severe and critical cases, adjunct to common therapy, may bring very beneficial results. Further, due to their autogenic sources, these transplants have not the risk of immune rejection. Furthermore, this technology could provide the lung involvement model for each specific patient leading to a better perception of the different courses of the disease and also iPSC technology has the potential to provide a platform for screening different antiviral drugs for each patient to offer the most efficient treatment tailored to each individual $[140,141]$. Novellus Inc. and CitiusPharma intend to employ iPS-derived MSC (NovoCiteMSC: NC-MSC) in a randomized placebo-controlled dose-inducing clinical trial followed by a dose level expansion to evaluate the safety and efficacy of this MSC-based product in those infected with COVID-19 using ARDS [142]. Initial cell source of these iPS cells is reprogrammed fibroblasts of a single individual. An iPSC cell bank would provide these iPS derived-MSCs for use in this trial [142]. Further, MultiStem is a new advanced clinical product derived from iPS sources or MAPC ${ }^{\circledR}$ [143]. This stem cell-based product has been provided to treat diverse diseases and indications such as inflammatory and immune, neurological, cardiovascular disease areas, etc. Atherys Inc., the Multistem producer, finished Phase I/II of the trial of IV infusion of this product in 26 patients infected with coronavirus. The results of this study have confirmed the safety in phase I, while phase II was performed a doubleblinded, placebo-controlled randomized experiment with a larger dosage [144]. Based on the results, the treatment group had short ICU times and lowered mortality without any adverse signs [144]. Hence, The Company is now leading a Phase II/III clinical trial to evaluate the safety and efficacy of Multistem for ARDS induced by coronavirus (NCT04367077) by enrolling 400 subjects [145].

\section{Synthetic Nano Stem Cells-based Therapy}

Leukaemia inhibitory factor (LIF) suggested as a crucial impact on offsetting the cytokine storm observed in the respiratory system when infected with viral pneumonia [146]. In the lungs, LIF as developed to regulate inflammation and concurrently repair the collateral injury to tiny blood capillaries and the alveoli thin air sacs where oxygen transfer happens [147]. By administering nanotechnology concepts on the producing simulated stem cells, the novel "LIFNano" revealed more potency comparing to soluble LIF [148, 149]. A study on the preclinical model of multiple sclerosis revealed that administering LIFNano could alter paralysis. The LIF is suggested to be critical for stimulating epithelial STAT3, which is necessary for lung alveoli's appropriate function. The treatment using exogenous LIF or LIF over-expression could restrict pulmonary inflammation in response to LPS or hypoxia [149]. The LIFNano can be administered as a substitute for cell-based therapy to refresh damaged areas and repress the cytokine storm patients infected with coronavirus.

\section{Next-Generation Stem Cell-Based Therapies}

More recently, the possibility of precise manipulation of the human genome using endonucleases (i.e., zinc finger nucleases and TALENS) and palindromic repeats (i.e., CRISPR) has opened a new window to the field of cell-based therapies [150] and has raised next-generation therapies which are more efficient and individually specific [151]. CRISPR/Cas13 system can cleave the SARS-CoV-2 RNA genome or inactivate the viral protein production after entering the infected cells [152]. The entrance process might be using a selective approach named ABACAS (AntiBody and CAS fusion). The ABACAS catch the virals protein as an antibody fragment [153]. In addition, ORF1a/b introduce as one of the best targets for CRISPR/Cas 13 activity inside the infected cells. Therefore, CRISPR technology can represent a more sensitive and specific treatment strategy for viral infections such as SARS-CoV-2 [152]. Next-generation stem cell-based therapies can deliver therapeutic drugs and improved therapeutic agents by themselves. Therefore, the new generation can edit mutations that lead to diseases or decline the allogeneic cells' immunogenicity by recruiting gene-editing platforms [151]. 


\section{Development of Cell-Based Therapy with Banking of Stem Cells}

The banking of autologous stem cells can be played a significant role in the expansion of regenerative and PM and is a fundamental approach to facilitate precision treatments in the clinic. Both MSCs and iPSCs can be store in cell banks to speed up using autologous sources in treatment strategies. Among multipotent somatic stem cells; HSCs of C.B. and MSCs of C.T. and AT represent the most accessible sources for each person. The history of cord blood banking refers to more than 20 years with more than 30,000 stem cell therapy and many applications in regenerative medicine. In contrast, cord tissue banking appeared over seven years ago, with more limited clinical applications [154]. On the other hand, Adipose tissue banking has paid great attention to clinical trials for more than ten years. It seems that this source of MSCs can be an appropriate alternative for BM-MSCs without their limitations.

Recently, iPSC banking is developing throughout the world to supply research and clinical needs. At present, several iPSCs banks in the USA, Europe, Korea, Japan, U.K., and Taiwan collect and store iPSCs from healthy or diseased people to understand the cellular mechanisms and drug discovery for personalized therapies. Some clinical trials are ongoing in this area. Further improvements in iPSC technology can more clarify their influence in regenerative medicine [98]. Although the expensiveness and time-consuming of the generation are essential barriers to achieving this aim, ongoing developments of iPSC banking can pave this road.

\section{Conclusion and Future Perspective}

COVID-19 caused a new pandemic and recruited many researchers from different biomedical fields to find solutions for prevention or treatments for its managing. However, the general treatment of COVID-19 depends on producing effective vaccines or drugs; the ARDS resulting from it needs to most powerful therapeutic management. In this view, PM and cellbased therapy find importance for most clinical investigations as a considerable candidate for therapeutic approaches [40]. Currently, there have been no approved cell-based therapeutic approaches to prevent or treat COVID-19 patients while several clinical trials are undergoing. Recently, MSCs have attracted attentions for clinical trials because of their immunomodulatory and regenerative properties. They could protect alveolar epithelial cells, repair the pulmonary microenvironment, prevent the pulmonary fibrosis, and help cure injured lungs [1]. Despite many completing and ongoing clinical trials, there is no clear conclusion regarding some issues related to MSCs limitations, including their safety, tumorigenicity, profibrogenicity, and heterogeneity [155]. Moreover, there are still doubting in providing the MSCs for a clinical scale, and consuming time and cost [59].

Moreover, it was reported that several stem cell-based clinical trials received approval for treating COVID-19 patients with acute respiratory distress. Therefore, stem cells can be played a crucial role in the management of this disease. Nextgeneration cell-based therapies can be used to edit mutations that lead to diseases or decline the allogeneic cells' immunogenicity by recruiting gene-editing platforms. These cells can be prepared based on specific features of each person to treat their specific diseases. The banking of stem cells and their products such as exosomes, E.V.s, and conditioned media can play an extraordinary role in the development of regenerative and PM and is a fundamental approach to facilitate precision treatments in the clinic [59]. There are some stem cell banks around the world that store somatic stem cells, iPSCs, and next-generation stem cells. However, more expansion and development in the banking of stem cells, especially those that can be used for precision treatments, facilitate PM approaches in the future. On the other hand, biomaterials can play a critical role in personalized cell therapies by mimicking individual cells' microenvironment to cell maintenance and immunoprotection. In summary, engineered cells using gene-editing platforms and precision biomaterials can develop personalized cell therapies with a broad range of clinical applications that may be usable in COVID-19 treatment, especially for ADRS.

The efficient treatment of COVID-19 needs a new attitude according to the different range of symptoms in different patients, and in this regard, PM can be had a central role. The clinical use of stem cells to treat COVID-19 is still some time away, but some promising reports reach positive results. Stem cell therapy, especially MSCs-based products, and even combination therapy to treat COVID-19 patients may be ideal therapeutic options.

As described earlier, stem cell-based therapy as a primary PM tool has started a new strategy to treat severe viral infections including COVID-19. This strategy can be continued by other novel cell-based therapies included immune cell therapies and Extracellular vesicles. However, MSCs seem a double-ended sword in COVID-19 treatment and need more studies in detail. Therefore, as new stem cell therapies are reported to usage in COVID-19 patients, clinical trials must be given to confirm their actual efficacy and possible side effects. Finally, personalized cell-based therapies can develop for the precision treatment of diseases such as COVID19 in the future.

Acknowledgments The authors appreciate Dr. Mohammad Hosein Amirzade-Iranaq that help in the editing of this paper.

Authors' Contributions A G conceptualized and finalized the study. All authors participated in drafting, writing, and editing of the manuscript and approved it for submission. 


\section{Compliance with Ethical Standards}

Confirmation Statement All authors confirm that their research is supported by their institutions primarily involved in education and research.

Author Disclosure Statement No competing financial interests exist.

\section{References}

1. Golchin, A., Seyedjafari, E., \& Ardeshirylajimi, A. (2020). Mesenchymal stem cell therapy for COVID-19: Present or future. Stem Cell Reviews and Reports. Springer, 16, 427-433. https:// doi.org/10.1007/s12015-020-09973-w.

2. Sohrabi, C., Alsafi, Z., O’Neill, N., Khan, M., Kerwan, A., AlJabir, A., ... Agha, R. (2020). World Health Organization declares global emergency: A review of the 2019 novel coronavirus (COVID-19). International Journal of Surgery. Elsevier Ltd. https://doi.org/10.1016/j.ijsu.2020.02.034, 76, 71, 76.

3. Munster, V. J., Koopmans, M., van Doremalen, N., van Riel, D., $\&$ de Wit, E. (2020). A novel coronavirus emerging in China Key questions for impact assessment. New England Journal of Medicine, 382(8), 692-694. https://doi.org/10.1056/ NEJMp2000929.

4. Zhu, N., Zhang, D., Wang, W., Li, X., Yang, B., Song, J., et al. (2020). A novel coronavirus from patients with pneumonia in China, 2019. New England Journal of Medicine, 382(8), 727 733. https://doi.org/10.1056/NEJMoa2001017.

5. Guo, Y. R., Cao, Q. D., Hong, Z. S., Tan, Y. Y., Chen, S. D., Jin, H. J., Tan, K. S., Wang, D. Y., \& Yan, Y. (2020, March 13). The origin, transmission and clinical therapies on coronavirus disease 2019 (COVID-19) outbreak- a n update on the status. Military Medical Research. BioMed Central Ltd., 7, 11. https://doi.org/ 10.1186/s40779-020-00240-0.

6. Influenza (Flu) Antiviral Drugs and Related Information | FDA. (n.d.). Retrieved November 13, 2020, from https://www.fda.gov/ drugs/information-drug-class/influenza-flu-antiviral-drugs-andrelated-information\#ApprovedDrugs

7. Influenza A (H1N1) 2009 Monovalent |FDA. (n.d.). Retrieved November 13, 2020, from https://www.fda.gov/vaccines-bloodbiologics/vaccines/influenza-h1n1-2009-monovalent

8. Cancio, M., Ciccocioppo, R., Rocco, P. R. M., Levine, B. L., Bronte, V., Bollard, C. M., Weiss, D., Boelens, J. J., \& Hanley, P. J. (2020). Emerging trends in COVID-19 treatment: Learning from inflammatory conditions associated with cellular therapies. Cytotherapy, 22(9), 474-481. https://doi.org/10.1016/j.jcyt.2020. 04.100.

9. Lafond, K. E., Nair, H., Rasooly, M. H., Valente, F., Booy, R., Rahman, M., et al. (2016). Global role and burden of influenza in pediatric respiratory hospitalizations, 1982-2012: A systematic analysis. PLoS Medicine, 13(3), e1001977. https://doi.org/10. 1371/journal.pmed.1001977.

10. Consensus document on the epidemiology of severe acute respiratory syndrome (SARS) . (2003). Retrieved from moz-extension://2dd2edd5-6a11-484d-8447-b2df5ab45137/enhancedreader.html?openApp\&pdf=https $\% 3 \mathrm{~A} \% 2 \mathrm{~F} \% 2 \mathrm{Fwww}$. who.int $\%$ 2Fcsr\%2Fsars\%2Fen\%2FWHOconsensus.pdf.

11. Petersen, E., Koopmans, M., Go, U., Hamer, D. H., Petrosillo, N., Castelli, F., Storgaard, M., al Khalili, S., \& Simonsen, L. (2020). Comparing SARS-CoV-2 with SARS-CoV and influenza pandemics. The Lancet Infectious Diseases, 20(9), e238-e244. https://doi.org/10.1016/S1473-3099(20)30484-9.
12. WHO $\mid$ Middle East respiratory syndrome coronavirus (MERSCoV). (2020). WHO. Retrieved from http://www.who.int/ emergencies/mers-cov/en/

13. Sánchez-Guijo, F., García-Arranz, M., López-Parra, M., Monedero, P., Mata-Martínez, C., Santos, A., ... Prósper, F. (2020). Adipose-derived mesenchymal stromal cells for the treatment of patients with severe SARS-CoV-2 pneumonia requiring mechanical ventilation. A proof of concept study. EClinicalMedicine, O(0). https://doi.org/10.1016/j.eclinm.2020. 100454.

14. COVID-19: Who's at higher risk of serious symptoms? - Mayo Clinic. (2020). Retrieved November 17, 2020, from https://www. mayoclinic.org/diseases-conditions/coronavirus/in-depth/ coronavirus-who-is-at-risk/art-20483301

15. Lim, S., Bae, J. H., Kwon, H. S., \& Nauck, M. A. (2020). COVID19 and diabetes mellitus: From pathophysiology to clinical management. Nature Reviews Endocrinology., 17, 11-30. https://doi. org/10.1038/s41574-020-00435-4.

16. Group, T. S. C.-19 G. (2020). Genomewide association study of severe Covid-19 with respiratory failure. New England Journal of Medicine, 383(16), 1522-1534. https://doi.org/10.1056/ nejmoa2020283.

17. Khoury, M., Cuenca, J., Cruz, F. F., Figueroa, F. E., Rocco, P. R. M., \& Weiss, D. J. (2020, June 1). Current status of cell-based therapies for respiratory virus infections: Applicability to COVID19. The European respiratory journal. NLM (Medline)., 55, 2000858. https://doi.org/10.1183/13993003.00858-2020.

18. Tang, B., Bragazzi, N. L., Li, Q., Tang, S., Xiao, Y., \& Wu, J. (2020). An updated estimation of the risk of transmission of the novel coronavirus (2019-nCov). Infectious Disease Modelling, 5, 248-255. https://doi.org/10.1016/j.idm.2020.02.001.

19. Lu, R., Zhao, X., Li, J., Niu, P., Yang, B., Wu, H., Wang, W., Song, H., Huang, B., Zhu, N., Bi, Y., Ma, X., Zhan, F., Wang, L., Hu, T., Zhou, H., Hu, Z., Zhou, W., Zhao, L., Chen, J., Meng, Y., Wang, J., Lin, Y., Yuan, J., Xie, Z., Ma, J., Liu, W. J., Wang, D., Xu, W., Holmes, E. C., Gao, G. F., Wu, G., Chen, W., Shi, W., \& Tan, W. (2020). Genomic characterisation and epidemiology of 2019 novel coronavirus: Implications for virus origins and receptor binding. The Lancet, 395(10224), 565-574. https://doi.org/10. 1016/S0140-6736(20)30251-8.

20. Zhou, P., Yang, X. L., Wang, X. G., Hu, B., Zhang, L., Zhang, W., Si, H. R., Zhu, Y., Li, B., Huang, C. L., Chen, H. D., Chen, J., Luo, Y., Guo, H., Jiang, R. D., Liu, M. Q., Chen, Y., Shen, X. R., Wang, X., Zheng, X. S., Zhao, K., Chen, Q. J., Deng, F., Liu, L. L., Yan, B., Zhan, F. X., Wang, Y. Y., Xiao, G. F., \& Shi, Z. L. (2020). A pneumonia outbreak associated with a new coronavirus of probable bat origin. Nature, 579(7798), 270-273. https://doi. org/10.1038/s41586-020-2012-7.

21. Leng, Z., Zhu, R., Hou, W., Feng, Y., Yang, Y., Han, Q., et al. (2020). Transplantation of ACE2- Mesenchymal stem cells improves the outcome of patients with covid-19 pneumonia. Aging and Disease, 11(2), 216-228. https://doi.org/10.14336/AD.2020. 0228 .

22. Hamming, I., Timens, W., Bulthuis, M. L. C., Lely, A. T., Navis, G. J., \& van Goor, H. (2004). Tissue distribution of ACE2 protein, the functional receptor for SARS coronavirus. A first step in understanding SARS pathogenesis. Journal of Pathology, 203(2), 631-637. https://doi.org/10.1002/path.1570.

23. Lippi, G., Lavie, C, J., \& Sanchis-Gomar, F. (2020). Cardiac troponin I in patients with coronavirus disease 2019 (COVID-19): Evidence from a meta-analysis. Progress in Cardiovascular Diseases. W.B. Saunders. https://doi.org/10.1016/j.pcad.2020. 03.001

24. Xu, L., Liu, J., Lu, M., Yang, D., \& Zheng, X. (2020). Liver injury during highly pathogenic human coronavirus infections. Liver 
International. Blackwell Publishing Ltd., 40, 998-1004. https:// doi.org/10.1111/liv.14435.

25. Zhao, X., Wang, K., Zuo, P., Liu, Y., Zhang, M., Xie, S., Zhang, H., Chen, X., \& Liu, C. (2020). Early decrease in blood platelet count is associated with poor prognosis in COVID-19 patientsIndications for predictive, preventive, and personalized medical approach. EPMA Journal, 11(2), 139-145. https://doi.org/10. 1007/s13167-020-00208-z.

26. Fauci, A. S., Lane, H. C., \& Redfield, R. R. (2020). Covid-19 navigating the uncharted. New England Journal of Medicine. Massachussetts Medical Society., 382, 1268-1269. https://doi. org/10.1056/NEJMe2002387.

27. Administration, D. (2020). Frequently Asked Questions for Veklury (remdesivir) updated 10/23/20. Retrieved from https:// www.gilead.com/news-and-press/press-room/press-.

28. Goldman, J. D., Lye, D. C. B., Hui, D. S., Marks, K. M., Bruno, R., Montejano, R., et al. (2020). Remdesivir for 5 or 10 days in patients with severe Covid-19. New England Journal of Medicine., 383, 1827-1837. https://doi.org/10.1056/nejmoa2001.

29. Li, X., Wang, Y., Agostinis, P., Rabson, A., Melino, G., Carafoli, E., Shi, Y., \& Sun, E. (2020). Is hydroxychloroquine beneficial for COVID-19 patients? Cell Death and Disease, 11(7), 1-6. https:// doi.org/10.1038/s41419-020-2721-8.

30. Mehta, P., McAuley, D. F., Brown, M., Sanchez, E., Tattersall, R. S., \& Manson, J. J. (2020). COVID-19: Consider cytokine storm syndromes and immunosuppression. The Lancet. Lancet Publishing Group., 395, 1033-1034. https://doi.org/10.1016/ S0140-6736(20)30628-0.

31. Sampson, A. K., Moritz, K. M., \& Denton, K. M. (2012). Postnatal ontogeny of angiotensin receptors and ACE2 in male and female rats. Gender Medicine, 9(1), 21-32. https://doi.org/10. 1016/j.genm.2011.12.003.

32. New partnership to sequence human genomes in the fight against coronavirus | Genomics England. (2020). Genomics England. Retrieved November 17, 2020, from https://www. genomicsengland.co.uk/genomics-england-genomicc-nhs-covid19/

33. Wang, F., Huang, S., Gao, H., Zhou, Y., Lai, C., Li, Z., et al. (2020). Initial whole genome sequencing and analysis of the host genetic contribution to COVID-19 severity and susceptibility. Cell Discovery., 6, 83. https://doi.org/10.1101/2020.06.09.20126607.

34. Mesoblast's remestemcel-L receives FDA IND clearance for treating COVID-19 patients with acute respiratory distress. (2020). Retrieved July 27, 2020, from https://smallcaps.com.au/ mesoblast-remestemcel-1-fda-ind-clearance-treating-covid-19patients-acute-respiratory-distress/

35. Ma, T., Xu, L., Ren, M., Shen, J., Han, Z., Sun, J., Zhao, Y., \& Liu, S. (2019). Novel genotype of infectious bronchitis virus isolated in China. Veterinary Microbiology, 230, 178-186. https:// doi.org/10.1016/j.vetmic.2019.01.020.

36. Cao, Y., Li, L., Feng, Z., Wan, S., Huang, P., Sun, X., Wen, F., Huang, X., Ning, G., \& Wang, W. (2020). Comparative genetic analysis of the novel coronavirus (2019-nCoV/SARS-CoV-2) receptor ACE2 in different populations. Cell Discov, 6, 11. https:// doi.org/10.1038/s41421-020-0147-1.

37. Wang, L.-Y., Cui, J.-J., OuYang, Q.-Y., Zhan, Y., Wang, Y.-M., Xu, X.-Y., ... Yin, J. (2020). Genetic profiles in Pharmacogenes indicate personalized drug therapy for COVID-19. medRxiv. https://doi.org/10.1101/2020.03.23.20041350.

38. Mansouri, F. (2017, June 1). The role of the clinical and molecular assays in prostate cancer detection. Asian Journal of Pharmaceutical and Clinical Research. Innovare academics sciences Pvt. 1td. https://doi.org/10.22159/ajpcr.2017.v10i6.17490.

39. Mansouri, F., Heydarzadeh, R., \& Yousefi, S. (2018). The association of interferon-gamma, interleukin-4 and interleukin-17 single-nucleotide polymorphisms with susceptibility to tuberculosis. APMIS, 126(3), 227-233. https://doi.org/10.1111/apm.12810.

40. Basiri, A., Pazhouhnia, Z., Beheshtizadeh, N., Hoseinpour, M., Saghazadeh, A., \& Rezaei, N. (2020). Regenerative medicine in COVID-19 treatment: Real opportunities and range of promises. Stem Cell Reviews and Reports. Springer. https://doi.org/10.1007/ s12015-020-09994-5.

41. Liu, H., Wang, L. L., Zhao, S. J., Kwak-Kim, J., Mor, G., \& Liao, A. H. (2020, June). Why are pregnant women susceptible to COVID-19? An immunological viewpoint. Journal of Reproductive Immunology. Elsevier Ireland Ltd., 139, 103122. https://doi.org/10.1016/j.jri.2020.103122.

42. Nejadghaderi, S, A., Heidari, A., Shakerian, N., Saghazadeh, A., \& Rezaei, N. (2020). Cardiovascular system is at higher risk of affecting by COVID-19. Acta Biomed, 91(3), ahead of print-ahead of print. https://doi.org/10.23750/abm.v91i3.9718.

43. Wu, Z., \& McGoogan, J. M. (2020, April). Characteristics of and important lessons from the coronavirus disease 2019 (COVID-19) outbreak in China: Summary of a report of 72314 cases from the Chinese Center for Disease Control and Prevention. JAMA Journal of the American Medical Association. American Medical Association., 323, 1239. https://doi.org/10.1001/jama. 2020.2648

44. Greater Risk of Severe COVID-19 in Black, Asian and Minority Ethnic Populations Is Not Explained by Cardiometabolic, Socioeconomic or Behavioural Factors, or by $25(\mathrm{OH})$-vitamin D Status: Study of 1326 Cases From the UK Biobank - PubMed. (n.d.).

45. Gérard, C., Maggipinto, G., \& Minon, J. M. (2020). COVID-19 and $\mathrm{ABO}$ blood group: Another viewpoint. British Journal of Haematology. Blackwell Publishing Ltd., 190, e93-e94. https:// doi.org/10.1111/bjh.16884.

46. Tamara, A., \& Tahapary, D. L. (2020). Obesity as a predictor for a poor prognosis of COVID-19: A systematic review. Diabetes and Metabolic Syndrome: Clinical Research and Reviews, 14(4), 655659. https://doi.org/10.1016/j.dsx.2020.05.020.

47. Vardavas, C, I., \& Nikitara, K. (2020). COVID-19 and smoking: A systematic review of the evidence. Tobacco Induced Diseases, 18(march). https://doi.org/10.18332/TID/119324.

48. Verity, R., Okell, L. C., Dorigatti, I., Winskill, P., Whittaker, C., Imai, N., Cuomo-Dannenburg, G., Thompson, H., Walker, P. G. T., Fu, H., Dighe, A., Griffin, J. T., Baguelin, M., Bhatia, S., Boonyasiri, A., Cori, A., Cucunubá, Z., FitzJohn, R., Gaythorpe, K., Green, W., Hamlet, A., Hinsley, W., Laydon, D., NedjatiGilani, G., Riley, S., van Elsland, S., Volz, E., Wang, H., Wang, Y., Xi, X., Donnelly, C. A., Ghani, A. C., \& Ferguson, N. M. (2020). Estimates of the severity of coronavirus disease 2019: A model-based analysis. The Lancet Infectious Diseases, 20(6), 669-677. https://doi.org/10.1016/S1473-3099(20)30243-7.

49. Li, W., Moore, M. J., Vasllieva, N., Sui, J., Wong, S. K., Berne, M. A., et al. (2003). Angiotensin-converting enzyme 2 is a functional receptor for the SARS coronavirus. Nature, 426(6965), 450-454. https://doi.org/10.1038/nature02145.

50. Darbani, B. (2020). The expression and polymorphism of entry machinery for covid-19 in human: Juxtaposing population groups, gender, and different tissues. International Journal of Environmental Research and Public Health, 17(10). https://doi. org/10.3390/ijerph17103433.

51. Wan, S., Yi, Q., Fan, S., Lv, J., Zhang, X., Guo, L., Lang, C., Xiao, Q., Xiao, K., Yi, Z., Qiang, M., Xiang, J., Zhang, B., Chen, Y., \& Gao, C. (2020). Relationships among lymphocyte subsets, cytokines, and the pulmonary inflammation index in coronavirus (COVID-19) infected patients. British Journal of Haematology, 189(3), 428-437. https://doi.org/10.1111/bjh.16659.

52. Shimabukuro-Vornhagen, A., Gödel, P., Subklewe, M., Stemmler, H. J., Schlößer, H. A., Schlaak, M., Kochanek, M., 
Böll, B., \& von Bergwelt-Baildon, M. S. (2018, June). Cytokine release syndrome. Journal for ImmunoTherapy of Cancer. BioMed Central Ltd., 6, 56. https://doi.org/10.1186/s40425-0180343-9.

53. Chen, G., Wu, D., Guo, W., Cao, Y., Huang, D., Wang, H., Wang, T., Zhang, X., Chen, H., Yu, H., Zhang, X., Zhang, M., Wu, S., Song, J., Chen, T., Han, M., Li, S., Luo, X., Zhao, J., \& Ning, Q. (2020). Clinical and immunological features of severe and moderate coronavirus disease 2019. Journal of Clinical Investigation, 130(5), 2620-2629. https://doi.org/10.1172/JCI137244.

54. Kehinde, T. A., \& Osundiji, M. A. (2020). Sickle cell trait and the potential risk of severe coronavirus disease 2019- A mini-review. European Journal of Haematology., 105, 519-523. https://doi. org/10.1111/ejh.13478.

55. Wang, M., Zhou, Y., Zong, Z., Liang, Z., Cao, Y., Tang, H., Song, B., Huang, Z., Kang, Y., Feng, P., Ying, B., \& Li, W. (2020). A precision medicine approach to managing 2019 novel coronavirus pneumonia. Precision Clinical Medicine, 3(1), 14-21. https://doi. org/10.1093/pcmedi/pbaa002.

56. Liu, M, A. (2019). A comparison of plasmid DNA and mRNA as vaccine technologies. Vaccines. MDPI AG. https://doi.org/10. 3390/vaccines 7020037, 7.

57. Kumar, V. (2019). Natural killer cells in sepsis: Underprivileged innate immune cells. European Journal of Cell Biology. Elsevier GmbH., 98, 81-93. https://doi.org/10.1016/j.ejcb.2018.12.003.

58. Fehniger, T. A., \& Cooper, M. A. (2016). Harnessing NK cell memory for Cancer Immunotherapy. Trends in Immunology. Elsevier Ltd., 37, 877-888. https://doi.org/10.1016/j.it.2016.09. 005 .

59. Golchin, A. (2020). Cell-Based Therapy for Severe COVID-19 Patients: Clinical Trials and Cost-Utility. Stem Cell Reviews and Reports, 1-7. https://doi.org/10.1007/s12015-020-10046-1

60. Market, M., Angka, L., Martel, A, B., Bastin, D., Olanubi, O., Tennakoon, G., ... Auer, R, C. (2020, June 23). Flattening the COVID-19 curve with natural killer cell based immunotherapies. Frontiers in Immunology. Frontiers Media S.A. https://doi.org/10. 3389/fimmu.2020.01512

61. Vidal, S, M., Khakoo, S, I., \& Biron, C, A. (2011). Natural killer cell responses during viral infections: Flexibility and conditioning of innate immunity by experience. Current Opinion in Virology. Elsevier B.V. https://doi.org/10.1016/j.coviro.2011.10.017

62. The Science Advisory Board staff writers. (2020). Novocellbio's COVID-19 cell therapy shows promising results. Retrieved August 20, 2020, from https://www.scienceboard.net/index. aspx? $?$ sec $=$ sup \&sub $=$ can \&pag $=$ dis \&ItemID $=1156$

63. Dutton, L. C., Dudhia, J., Catchpole, B., Hodgkiss-Geere, H., Werling, D., \& Connolly, D. J. (2018). Cardiosphere-derived cells suppress allogeneic lymphocytes by production of PGE2 acting via the EP4 receptor. Scientific Reports, 8(1), 1-14. https://doi. org/10.1038/s41598-018-31569-1.

64. Singh, S., Chakravarty, T., Chen, P., Akhmerov, A., Falk, J., Friedman, O., Zaman, T., Ebinger, J. E., Gheorghiu, M., Marbán, L., Marbán, E., \& Makkar, R. R. (2020). Allogeneic cardiosphere-derived cells (CAP-1002) in critically ill COVID19 patients: Compassionate-use case series. Basic Research in Cardiology, 115(4), 36. https://doi.org/10.1007/s00395-0200795-1.

65. Golchin, A., Hosseinzadeh, S., \& Ardeshirylajimi, A. (2018). The exosomes released from different cell types and their effects in wound healing. Journal of Cellular Biochemistry, 119(7), 50435052. https://doi.org/10.1002/jcb.26706.

66. Mansouri, F., \& Seyed Mohammadzad, M. H. (2020). Molecular miR-19a in acute myocardial infarction: Novel potential indicators of prognosis and early diagnosis. Asian Pacific Journal of Cancer Prevention, 21(4), 975-982. https://doi.org/10.31557/apjcp.2020. 21.4.975.
67. Abraham, A., \& Krasnodembskaya, A. (2020). Mesenchymal stem cell-derived extracellular vesicles for the treatment of acute respiratory distress syndrome. Stem Cells Translational Medicine. John Wiley and Sons Ltd., 9, 28-38. https://doi.org/10.1002/sctm. 19-0205.

68. Gupta, A., Kashte, S., Gupta, M., Rodriguez, H. C., Gautam, S. S., \& Kadam, S. (2020). Mesenchymal stem cells and exosome therapy for COVID-19: Current status and future perspective. Human Cell. Springer Japan., 33, 907-918. https://doi.org/10.1007/ s13577-020-00407-w.

69. Qian, X., Xu, C., Fang, S., Zhao, P., Wang, Y., Liu, H., Yuan, W., \& Qi, Z. (2016). Exosomal MicroRNAs derived from umbilical Mesenchymal stem cells inhibit hepatitis C virus infection. Stem Cells Translational Medicine, 5(9), 1190-1203. https://doi.org/ 10.5966/sctm.2015-0348.

70. Wang, M., Yuan, Q., \& Xie, L. (2018). Mesenchymal stem cellbased immunomodulation: Properties and clinical application. Stem Cells International. Hindawi Limited., 2018, 1-12. https:// doi.org/10.1115/2018/3057624.

71. Worthington, E, N., \& Hagood, J, S. (2020). Therapeutic use of extracellular vesicles for acute and chronic lung disease. International Journal of Molecular Sciences. MDPI AG. https:// doi.org/10.3390/ijms21072318, 21.

72. Yin, K., Wang, S., \& Zhao, R. C. (2019). Exosomes from mesenchymal stem/stromal cells: A new therapeutic paradigm. Biomarker Research. BioMed Central Ltd., 7, 8. https://doi.org/ 10.1186/s40364-019-0159-x.

73. Khatri, M., Richardson, L. A., \& Meulia, T. (2018). Mesenchymal stem cell-derived extracellular vesicles attenuate influenza virusinduced acute lung injury in a pig model. Stem Cell Research and Therapy, 9(1), 17. https://doi.org/10.1186/s13287-018-0774-8.

74. Sengupta, V., Sengupta, S., Lazo, A., Woods, P., Nolan, A., \& Bremer, N. (2020). Exosomes derived from bone marrow Mesenchymal stem cells as treatment for severe COVID-19. Stem Cells and Development, 29(12), 747-754. https://doi.org/ 10.1089/scd.2020.0080.

75. Cruz, F. F., Borg, Z. D., Goodwin, M., Sokocevic, D., Wagner, D. E., Coffey, A., Antunes, M., Robinson, K. L., Mitsialis, S. A., Kourembanas, S., Thane, K., Hoffman, A. M., McKenna, D. H., Rocco, P. R. M., \& Weiss, D. J. (2015). Systemic Administration of Human Bone Marrow-Derived Mesenchymal Stromal Cell Extracellular Vesicles Ameliorates Aspergillus Hyphal ExtractInduced Allergic Airway Inflammation in Immunocompetent mice. Stem Cells Translational Medicine, 4(11), 1302-1316. https://doi.org/10.5966/sctm.2014-0280.

76. Bari, E., Ferrarotti, I., Saracino, L., Perteghella, S., Torre, M. L., \& Corsico, A. G. (2020). Mesenchymal stromal cell Secretome for severe COVID-19 infections: Premises for the therapeutic use. Cells, 9(4), 5-9. https://doi.org/10.3390/cells9040924.

77. Zhao, R. C. (2020). Stem cell-based therapy for coronavirus disease 2019. Stem Cells and Development, 29(11), 679-681. https:// doi.org/10.1089/scd.2020.0071.

78. Atala, A., Lanza, R., Thomson, J, A., \& Nerem, R, M. (2008). Principles of regenerative medicine. Principles of Regenerative Medicine. Elsevier Inc. https://doi.org/10.1016/B978-0-12369410-2.X5001-3.

79. THOMAS, E. D., LOCHTE, H. L., CANNON, J. H., SAHLER, O. D., \& FERREBEE, J. W. (1959). Supralethal whole body irradiation and isologous marrow transplantation in man. The Journal of clinical investigation, 38(10 Pt 1-2), 1709-1716. https://doi. org/10.1172/JCI103949.

80. Hass, R., Kasper, C., Böhm, S., \& Jacobs, R. Different populations and sources of human mesenchymal stem cells (MSC): A comparison of adult and neonatal tissue-derived MSC. , 9 Cell Communication and Signaling 12 (2011). BioMed Central. https://doi.org/10.1186/1478-811X-9-12. 
81. Engelhardt, M., Douville, J., Behringer, D., Jähne, A., Smith, A., Henschler, R., \& Lange, W. (2001). Hematopoietic recovery of ex vivo perfusion culture expanded bone marrow and unexpanded peripheral blood progenitors after myeloablative chemotherapy. Bone Marrow Transplantation, 27(3), 249-259. https://doi.org/ 10.1038/sj.bmt.1702788.

82. Ishii, T. (2014). Fetal stem cell transplantation: Past, present, and future. World Journal of Stem Cells, 6(4), 404-420. https://doi. org/10.4252/wjsc.v6.i4.404.

83. Williams, L. A., Davis-Dusenbery, B. N., \& Eggan, K. C. (2012). SnapShot: Directed differentiation of pluripotent stem cells. Cell, 149(5), 1174-1174.e1. https://doi.org/10.1016/j.cell.2012.05.015.

84. Thomson, J. A., Itskovitz-Eldor, J., Shapiro, S. S., Waknitz, M. A., Swiergiel, J. J., Marshall, V. S., \& Jones, J. M. (1998). Embryonic stem cell lines derived from human blastocysts. Science (New York, N.Y.), 282(5391), 1145-1147. https://doi.org/10.1126/ science.282.5391.1145.

85. Takahashi, K., Tanabe, K., Ohnuki, M., Narita, M., Ichisaka, T., Tomoda, K., \& Yamanaka, S. (2007). Induction of pluripotent stem cells from adult human fibroblasts by defined factors. Cell, 131(5), 861-872. https://doi.org/10.1016/j.cell.2007.11.019.

86. Golchin, A., Chatziparasidou, A., Ranjbarvan, P., Niknam, Z., \& Ardeshirylajimi, A. (2020). Embryonic stem cells in clinical trials: Current overview of developments and challenges. In Advances in Experimental Medicine and Biology (pp. 1-19). Springer, New York, NY. https://doi.org/10.1007/5584_2020_592

87. Harris, D. T. (2014). Stem cell banking for regenerative and personalized medicine. Biomedicines. MDPI AG., 2, 50-79. https:// doi.org/10.3390/biomedicines2010050.

88. RS, M. (2016). Stem cells applications in regenerative medicine and disease therapeutics. International journal of cell biology, 2016. https://doi.org/10.1155/2016/6940283.

89. Norambuena, G. A., Khoury, M., \& Jorgensen, C. (2012). Mesenchymal stem cells in osteoarticular pediatric diseases: An update. Pediatric research. Nature Publishing Group., 71, 452458. https://doi.org/10.1038/pr.2011.68.

90. Pati, S., Gerber, M. H., Menge, T. D., Wataha, K. A., Zhao, Y., Baumgartner, J. A., Zhao, J., Letourneau, P. A., Huby, M. P., Baer, L. A., Salsbury, J. R., Kozar, R. A., Wade, C. E., Walker, P. A., Dash, P. K., Cox, C. S., Doursout, M. F., \& Holcomb, J. B. (2011). Bone marrow derived mesenchymal stem cells inhibit inflammation and preserve vascular endothelial integrity in the lungs after hemorrhagic shock. PLoS One, 6(9), 25171. https://doi.org/ 10.1371/journal.pone.0025171.

91. Choudhery, M. S., Khan, M., Mahmood, R., Mohsin, S., Akhtar, S., Ali, F., Khan, S. N., \& Riazuddin, S. (2012). Mesenchymal stem cells conditioned with glucose depletion augments their ability to repair-infarcted myocardium. Journal of Cellular and Molecular Medicine, 16(10), 2518-2529. https://doi.org/10. 1111/j.1582-4934.2012.01568.x.

92. Choudhery, M. S., Khan, M., Mahmood, R., Mehmood, A., Khan, S. N., \& Riazuddin, S. (2012). Bone marrow derived mesenchymal stem cells from aged mice have reduced wound healing, angiogenesis, proliferation and anti-apoptosis capabilities. Cell Biology International, 36(8), 747-753. https://doi.org/10.1042/ cbi20110183.

93. See, E. Y.-S., Toh, S. L., \& Goh, J. C. H. (2010). Multilineage potential of bone-marrow-derived Mesenchymal stem cell cell sheets: Implications for tissue engineering. Tissue Engineering Part A, 16(4), 1421-1431. https://doi.org/10.1089/ten.tea.2009. 0501.

94. Strioga, M., Viswanathan, S., Darinskas, A., Slaby, O., \& Michalek, J. (2012). Same or not the same? Comparison of adipose tissue-derived versus bone marrow-derived mesenchymal stem and stromal cells. Stem Cells and Development. Mary Ann
Liebert, Inc. 140 Huguenot street, 3rd floor New Rochelle, NY 10801 USA . https://doi.org/10.1089/scd.2011.0722.

95. Lindroos, B., Suuronen, R., \& Miettinen, S. (2011). The potential of adipose stem cells in regenerative medicine. Stem Cell Reviews and Reports. Stem Cell Rev Rep., 7, 269-291. https://doi.org/10. 1007/s12015-010-9193-7.

96. Cao, Y., Li, L., Feng, Z., Wan, S., Huang, P., Sun, X., Wen, F., Huang, X., Ning, G., \& Wang, W. (2020). Comparative genetic analysis of the novel coronavirus (2019-nCoV/SARS-CoV-2) receptor ACE2 in different populations. Cell Discov, 6(1), 11. https://doi.org/10.1038/s41421-020-0147-1.

97. Golchin, A., Farahany, T. Z. T. Z. T. Z., Khojasteh, A., Soleimanifar, F., Ardeshirylajimi, A., Soleimanifar, F., \& Ardeshirylajimi, A. (2018). The clinical trials of mesenchymal stem cell therapy in skin diseases: An update and concise review. Current Stem Cell Research \& Therapy, 13(1), 22-33. https://doi. org/10.2174/1574888X13666180913123424.

98. Huang, C. Y., Liu, C. L., Ting, C. Y., Chiu, Y. T., Cheng, Y. C., Nicholson, M. W., \& Hsieh, P. C. H. (2019). Human iPSC banking: Barriers and opportunities. Journal of Biomedical Science. BioMed Central Ltd., 26, 87. https://doi.org/10.1186/s12929019-0578-x.

99. Ren, G., Zhang, L., Zhao, X., Xu, G., Zhang, Y., cell, A. R.-C. stem, \& 2008, undefined. (n.d.). Mesenchymal stem cell-mediated immunosuppression occurs via concerted action of chemokines and nitric oxide. Elsevier

100. Alshehri, N., \& Almutairi, A. (2016). Phenotypic and functional characterization of Mesenchymal stem/multipotent stromal cells from decidua Parietalis of human term placenta. journals.sagepub.com, 23(9), 1193-1207. https://doi.org/10. $1177 / 1933719116632924$.

101. Su, J., Chen, X., Huang, Y., Li, W., Li, J., ... K. C.-C. D. \&, \& 2014, undefined. (n.d.). Phylogenetic distinction of iNOS and IDO function in mesenchymal stem cell-mediated immunosuppression in mammalian species. nature.com.

102. Bai, L., Lennon, D., Caplan, A., ... A. D.-N., \& 2012, undefined. (n.d.). Hepatocyte growth factor mediates mesenchymal stem cell-induced recovery in multiple sclerosis models. nature.com.

103. Watanabe, Y., Tsuchiya, A., Seino, S., Kawata, Y., Kojima, Y., Ikarashi, S., Starkey Lewis, P. J., Lu, W. Y., Kikuta, J., Kawai, H., Yamagiwa, S., Forbes, S. J., Ishii, M., \& Terai, S. (2019). Mesenchymal stem cells and induced bone marrow-derived macrophages synergistically improve liver fibrosis in mice. Stem Cells Translational Medicine, 8(3), 271-284. https://doi.org/10.1002/ sctm.18-0105.

104. Ikarashi, S., Tsuchiya, A., Kawata, Y., Kojima, Y., Watanabe, T., Takeuchi, S., Igarashi, K., Ideta-Otsuka, M., Oki, K., Takamura, M., \& Terai, S. (2019). Effects of human adipose tissue-derived and umbilical cord tissue-derived Mesenchymal stem cells in a dextran sulfate sodium-induced mouse model. BioResearch Open Access, 8(1), 185-199. https://doi.org/10.1089/biores. 2019.0022

105. Golchin, A., Farahany, T. Z., Khojasteh, A., Soleimanifar, F., \& Ardeshirylajimi, A. (2018). The clinical trials of Mesenchymal stem cell therapy in skin diseases: An update and concise review. Current Stem Cell Research \& Therapy, 14(1), 22-33. https://doi. org/10.2174/1574888x13666180913123424.

106. Golchin, A., \& Farahany, T. Z. T. Z. (2019). Biological products: Cellular therapy and FDA approved products. Stem Cell Reviews and Reports, 15(2), 1-10. https://doi.org/10.1007/s12015-0189866-1.

107. Aggarwal, S., Blood, M. P., \& 2005, undefined. (n.d.). Human mesenchymal stem cells modulate allogeneic immune cell responses. ashpublications.org. 
108. Corcione, A., Benvenuto, F., Ferretti, E., Blood, D. G., \& 2006, undefined. (n.d.). Human mesenchymal stem cells modulate Bcell functions. ashpublications.org.

109. Goolaerts, A., Pellan-Randrianarison, N., Larghero, J., Vanneaux, V., Uzunhan, Y., Gille, T., Dard, N., Planès, C., Matthay, M. A., \& Clerici, C. (2014). Conditioned media from mesenchymal stromal cells restore sodium transport and preserve epithelial permeability in an in vitro model of acute alveolar injury. American Journal of Physiology - Lung Cellular and Molecular Physiology, 306(11), L975-L985. https://doi.org/10.1152/ajplung.00242.2013.

110. Krasnodembskaya, A., Song, Y., Fang, X., Gupta, N., Serikov, V., Lee, J. W., \& Matthay, M. A. (2010). Antibacterial effect of human mesenchymal stem cells is mediated in part from secretion of the antimicrobial peptide LL-37. Stem Cells, 28(12), 2229-2238. https://doi.org/10.1002/stem.544.

111. Islam, M., Das, S., Emin, M., Wei, M., medicine, L. S.-N., \& 2012, undefined. (n.d.). Mitochondrial transfer from bone-marrow-derived stromal cells to pulmonary alveoli protects against acute lung injury. nature.com.

112. Lukomska, B., Stanaszek, L., Zuba-Surma, E., Legosz, P., Sarzynska, S., \& Drela, K. (2019). Challenges and controversies in human Mesenchymal stem cell therapy. Stem Cells International. Hindawi Limited., 2019, 1-10. https://doi.org/10. $1155 / 2019 / 9628536$

113. Shetty, A. K. (2020). Mesenchymal stem cell infusion shows promise for combating coronavirus (COVID-19)-induced pneumonia. Aging and Disease. International society on aging and disease. https://doi.org/10.14336/AD.2020.0301.

114. Kavianpour, M., Saleh, M., \& Verdi, J. (2020). The role of mesenchymal stromal cells in immune modulation of COVID-19: Focus on cytokine storm. Stem Cell Research and Therapy. BioMed Central Ltd., 11, 404. https://doi.org/10.1186/s13287020-01849-7.

115. Wang, Y., Chen, X., Cao, W., immunology, Y. S.-N., \& 2014, undefined. (n.d.). Plasticity of mesenchymal stem cells in immunomodulation: pathological and therapeutic implications. nature.com

116. Aboalola, D., international, V. H.-S. cells, \& 2017, undefined. (n.d.). Different effects of insulin-like growth factor-1 and insulin-like growth factor-2 on myogenic differentiation of human mesenchymal stem cells. hindawi.com.

117. Gebler, A., Zabel, O., medicine, B. S.-T. in molecular, \& 2012, undefined. (n.d.). The immunomodulatory capacity of mesenchymal stem cells. Elsevier

118. Wang, M., Yuan, Q., international, L. X.-S. cells, \& 2018, undefined. (n.d.). Mesenchymal stem cell-based immunomodulation: properties and clinical application. hindawi.com.

119. Khoury, M., Cuenca, J., ... F. C.-E., \& 2020, undefined. (n.d.). Current status of cell-based therapies for respiratory virus infections: Applicability to COVID-19. Eur Respiratory Soc.

120. Atluri, S., Manchikanti, L., \& Hirsch, J. A. (2020). Expanded umbilical cord mesenchymal stem cells (UC-MSCs) as a therapeutic strategy in managing critically ill COVID-19 patients: the case for compassionate. Pain Physician, 23(2), E71-E83.

121. Rocha, J, L, M., de Oliveira, W, C, F., Noronha, N, C., dos Santos, N, C, D., Covas, D, T., Picanço-Castro, V., Swiech K. Malmegrim, K, C, R. (2020). Mesenchymal stromal cells in viral infections: Implications for COVID-19. Stem Cell Reviews and Reports. Springer. https://doi.org/10.1007/s12015-020-10032-7.

122. Kane, M., Zang, T. M., Rihn, S. J., Zhang, F., Kueck, T., Alim, M., Schoggins, J., Rice, C. M., Wilson, S. J., \& Bieniasz, P. D. (2016). Identification of interferon-stimulated genes with antiretroviral activity. Cell Host and Microbe, 20(3), 392-405. https:// doi.org/10.1016/j.chom.2016.08.005.

123. Shu, L., Niu, C., Li, R., Huang, T., Wang, Y., Huang, M., et al. (2020). Treatment of severe COVID-19 with human umbilical cord mesenchymal stem cells., 11(1), 361. https://doi.org/10. 1186/s13287-020-01875-5.

124

Liang, B., Chen, J., Li, T., Wu, H., Yang, W., Li, Y., Li, J., Yu, C., Nie, F., Ma, Z., Yang, M., Xiao, M., Nie, P., Gao, Y., Qian, C., \& $\mathrm{Hu}$, M. (2020). Clinical remission of a critically ill COVID-19 patient treated by human umbilical cord mesenchymal stem cells. Medicine, 99(31), e21429. https://doi.org/10.1097/MD. 0000000000021429 .

125. Tang, L., Jiang, Y., Zhu, M., Chen, L., Zhou, X., Zhou, C., Ye, P., Chen, X., Wang, B., Xu, Z., Zhang, Q., Xu, X., Gao, H., Wu, X., Li, D., Jiang, W., Qu, J., Xiang, C., \& Li, L. (2020). Clinical study using mesenchymal stem cells for the treatment of patients with severe COVID-19. Frontiers of Medicine, 14, 1-10. https://doi. org/10.1007/s11684-020-0810-9.

126. Chen, J., Hu, C., Chen, L., Tang, L., Zhu, Y., Xu, X., ... 2020, undefined. (n.d.). Study of mesenchymal stem cell treating acute respiratory distress syndrome induced by epidemic influenza a (H7N9) infection, a hint for COVID-19 treatment. Elsevier.

127. Leng, Z., Zhu, R., Hou, W., Feng, Y., Yang, Y., ... Q. Han and, \& 2020, undefined. (n.d.). Transplantation of ACE2-mesenchymal stem cells improves the outcome of patients with COVID-19 pneumonia. ncbi.nlm.nih.gov.

128. Meng, F., Xu, R., Wang, S., Xu, Z., Zhang, C., Li, Y., Yang, T., Shi, L., Fu, J., Jiang, T., Huang, L., Zhao, P., Yuan, X., Fan, X., Zhang, J. Y., Song, J., Zhang, D., Jiao, Y., Liu, L., Zhou, C., Maeurer, M., Zumla, A., Shi, M., \& Wang, F. S. (2020). Human umbilical cord-derived mesenchymal stem cell therapy in patients with COVID-19: A phase 1 clinical trial. Signal Transduction and Targeted Therapy, 5(1), 172. https://doi.org/10.1038/s41392-02000286-5.

129. U.S. FDA clears Plurisetm's IND application for Phase II COVID19 Study. (2020). Globe Newswire. Retrieved from https://www. globenewswire.com/news-release/2020/05/08/2030212/0/en/US-FDA-Clears-Pluristem-s-IND-Application-for-Phase-IICOVID-19-Study.html

130. Shetty, R., Murugeswari, P., Chakrabarty, K., Jayadev, C., Matalia, H., Ghosh, A., \& Das, D. (2020). Stem cell therapy in COVID-19 - Current evidence and future potential. Cytotherapy. https://doi.org/10.1016/j.jcyt.2020.11.001.

131. Maurya, C, K., Misra, R., Sharma, P., Singh, N., Awasthi, H., Agrawal, R., ... Dwivedi, S. (2020). Novel stem cells and nucleic acid-based vaccine trials against viral outbreak: A systematic evaluation during COVID-2019 pandemic. Indian Journal of Clinical Biochemistry, 1-13. https://doi.org/10.1007/s12291-020-009074.

132. Ardeshirylajimi, A. (2017). Applied induced pluripotent stem cells in combination with biomaterials in bone tissue engineering. Journal of Cellular Biochemistry, 118(10), 3034-3042. https:// doi.org/10.1002/jcb.25996.

133. Yu, J., Vodyanik, M. A., Smuga-Otto, K., Antosiewicz-Bourget, J., Frane, J. L., Tian, S., Nie, J., Jonsdottir, G. A., Ruotti, V., Stewart, R., Slukvin, I. I., \& Thomson, J. A. (2007). Induced pluripotent stem cell lines derived from human somatic cells. Science, 318(5858), 1917-1920. https://doi.org/10.1126/science. 1526.

134. Sayed, N., Liu, C., \& Wu, J. C. (2016). Translation of humaninduced pluripotent stem cells from clinical trial in a dish to precision medicine. Journal of the American College of Cardiology. Elsevier USA., 67, 2161-2176. https://doi.org/10.1016/j.jacc. 2016.01.083.

135. Merling, R. K., Sweeney, C. L., Choi, U., De Ravin, S. S., Myers, T. G., Otaizo-Carrasquero, F., et al. (2013). Transgene-free iPSCs generated from small volume peripheral blood nonmobilized CD34+ cells. Blood, 121(14), e98-e107. https://doi.org/10.1182/ blood-2012-03-420273. 
136. Wilson, K. D., \& Wu, J. C. (2015). Induced pluripotent stem cells. JAMA - Journal of the American Medical Association. American Medical Association., 313, 1613-1614. https://doi.org/10.1001/ jama.2015.1846.

137. Mitchell, A., Wanczyk, H., Jensen, T., \& Finck, C. (2019). Assessment of iPSC teratogenicity throughout directed differentiation toward an alveolar-like phenotype. Differentiation, 105, 4553. https://doi.org/10.1016/j.diff.2019.01.003.

138. Malik, N., \& Rao, M, S. (2013). A review of the methods for human iPSC derivation. In Methods in Molecular Biology (Vol. 997, pp. 23-33). NIH public access. https://doi.org/10.1007/9781-62703-348-0_3.

139. Carsana, L., Sonzogni, A., Nasr, A., Rossi, R. S., Pellegrinelli, A., Zerbi, P., Rech, R., Colombo, R., Antinori, S., Corbellino, M., Galli, M., Catena, E., Tosoni, A., Gianatti, A., \& Nebuloni, M. (2020). Pulmonary post-mortem findings in a series of COVID-19 cases from northern Italy: A two-Centre descriptive study. The Lancet Infectious Diseases, 20, 1135-1140. https://doi.org/10. 1016/S1473-3099(20)30434-5.

140. Abo, K, M., Ma, L., Matte, T., Huang, J., Alysandratos, K, D., Werder, R, B., ... Villacorta-Martin, C. (2020). Human iPSCderived alveolar and airway epithelial cells can be cultured at air-liquid interface and express SARS-CoV-2 host factors. bioRxiv, 2020.06.03.132639. https://doi.org/10.1101/2020.06.03. 132639.

141. Trevisan, M., Sinigaglia, A., Desole, G., Berto, A., Pacenti, M., Palù, G., \& Barzon, L. (2015, July). Modeling viral infectious diseases and development of antiviral therapies using human induced pluripotent stem cell-derived systems. Viruses. MDPI AG., 7, 3835-3856. https://doi.org/10.3390/v7072800.

142. Novel Stem Cell Therapy for COVID-19-related ARDS in Development | RT. (2020). Retrieved November 20, 2020, from https://rtmagazine.com/products-treatment/pharmaceuticals/uspharmaceuticals/stem-cells-covid-19-ards/

143. Athersys, Inc. - MultiStem Therapy - Overview. (2020). Retrieved November 20, 2020, from https://www.athersys.com/multistemtherapy/overview/default.aspx

144. Athersys, Inc. - Clinical Trials - Acute Respiratory Distress Syndrome (ARDS). (2020). Retrieved November 20, 2020, from https:/www.athersys.com/clinical-trials/ards/default.aspx

145. MultiStem Administration for COVID-19 Induced ARDS (MACoVIA) - Full Text View - ClinicalTrials.gov. (2020). Retrieved November 20, 2020, from https://www.clinicaltrials. gov/ct $2 /$ show $/$ NCT04367077? term=MultiStem\&cond $=$ Covid19\&draw $=2 \&$ rank $=1$

146. Foronjy, R. F., Dabo, A. J., Cummins, N., \& Geraghty, P. (2014). Leukemia inhibitory factor protects the lung during respiratory syncytial viral infection. BMC Immunology, 15(1), 41. https:// doi.org/10.1186/s12865-014-0041-4.

147. Metcalfe, S, M. (2020). COVID-19 lockdown: de-risking exit by protecting the lung with leukaemia inhibitory factor (LIF). Medicine in Drug Discovery, 6, 100043. https://doi.org/10.1016/ j.medidd.2020.100043.

148. Metcalfe, S, M., Strom, T, B., Williams, A., \& Fahmy, T, M. (n.d.). ARTICLE Nanobiomedicine Multiple Sclerosis and the LIF/IL-6 Axis: Use of Nanotechnology to Harness the Tolerogenic and Reparative Properties of LIF Invited Review Article. hrcak.srce.hr. https://doi.org/10.5772/60622

149. Metcalfe, S. M. (2020). Mesenchymal stem cells and management of COVID-19 pneumonia. Medicine in Drug Discovery, 100019. https://doi.org/10.1016/j.medidd.2020.100019, 100019.

150. Golchin, A., Shams, F., \& Karami, F. (2020). Advancing mesenchymal stem cell therapy with CRISPR/Cas9 for clinical trial studies. In Advances in Experimental Medicine and Biology (Vol. 1247, pp. 89-100). Springer. https://doi.org/10.1007/5584 2019_459, 2019.

151. Kimbrel, E. A., \& Lanza, R. (2020). Next-generation stem cells Ushering in a new era of cell-based therapies. Nature Reviews Drug Discovery. Nature Research., 19, 463-479. https://doi.org/ 10.1038/s41573-020-0064-x.

152. Lotfi, M., \& Rezaei, N. (2020). CRISPR/Cas13: A potential therapeutic option of COVID-19. Biomedicine and Pharmacotherapy. Elsevier Masson s.r.1. https://doi.org/10.1016/j.biopha.2020. 110738.

153. Nalawansha, D. A., \& Samarasinghe, K. T. G. (2020). Doublebarreled CRISPR technology as a novel treatment strategy for COVID-19. ACS Pharmacology \& Translational Science, 3(5), 790-800. https://doi.org/10.1021/acsptsci.0c00071.

154. Butler, M. G., \& Menitove, J. E. (2011). Umbilical cord blood banking: An update. Journal of Assisted Reproduction and Genetics, 28(8), 669-676. https://doi.org/10.1007/s10815-0119577-x.

155. Golchin, A., Rekabgardan, M., Taheri, R. A., \& Nourani, M. R. (2018). Promotion of cell-based therapy: Special focus on the cooperation of Mesenchymal stem cell therapy and gene therapy for clinical trial studies. In K. Turksen (Ed.), Advances in experimental medicine and biology (Vol. 1119, pp. 103-118). New York, NY: Springer. https://doi.org/10.1007/5584_2018_256.

Publisher's Note Springer Nature remains neutral with regard to jurisdictional claims in published maps and institutional affiliations. 